MPR Reference No.: 6091-180

MATHEMATICA

Policy Research, Inc.

\title{
Kauffman Firm Survey \\ (KFS) Baseline \\ Methodology Report
}

\section{Final Report}

October 24, 2007

Revised: January 23, 2008

\author{
David DesRoches \\ Tom Barton \\ Janice Ballou \\ Frank Potter \\ Zhanyun Zhao \\ Betsy Santos \\ Jaceey Sebastian
}

Submitted to:

Ewing Marion Kauffman Foundation 4801 Rockhill Road

Kansas City, MO 64110

Project Officer:

E.J. Reedy
Submitted by:

Mathematica Policy Research, Inc. P.O. Box 2393

Princeton, NJ 08543-2393

Telephone: (609) 799-3535

Facsimile: (609) 799-0005

Project Director:

David DesRoches 



\section{CONTENTS}

Page

A. EXECUTIVE SUMMARY 1

B. THE KAUFFMAN FIRM SURVEY: DESIGN AND PRETESTING ...................6

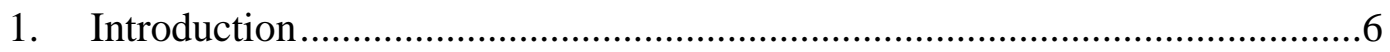

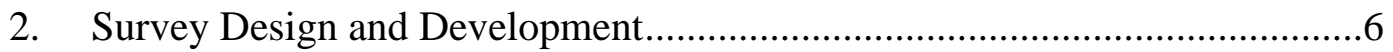

3. Literature Review and Technical Advisory Group .........................................

4. Initial Advisory Committee Meeting ...........................................................

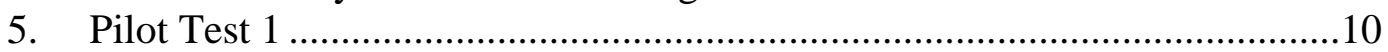

6. Questionnaire Development..........................................................................

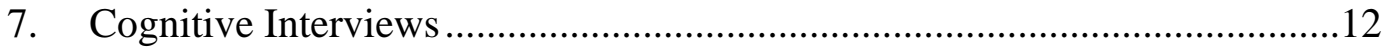

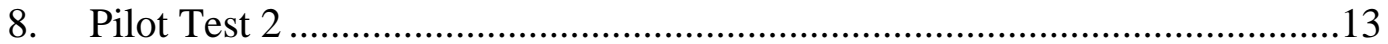

9. Screener and Questionnaire Content........................................................15

10. Instrument Development and Testing ........................................................19

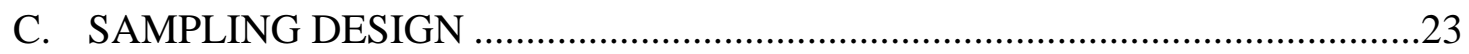

1. Target and Study Population.........................................................................23

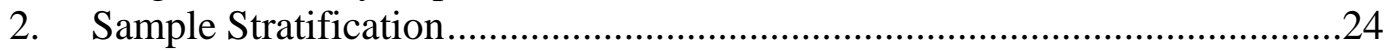

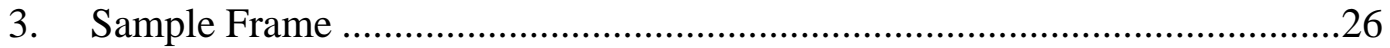

4. Sample Selection and Release ……………………...............................28

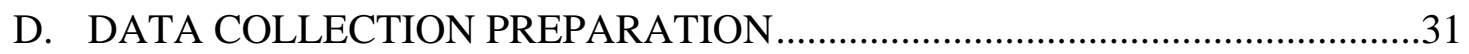

1. Respondent Materials Development ..........................................................

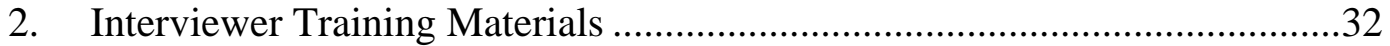

3. Survey Operations Center (SOC) Staff Training ...........................................33

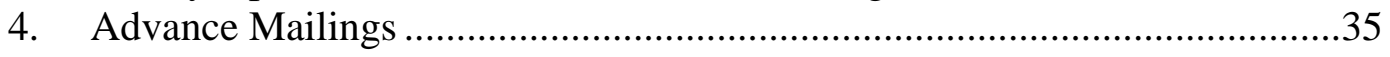

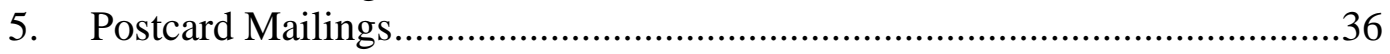

6. Response Protocols to Sample Member Inquiries ……………........................36

7. Respondent Incentives ................................................................................

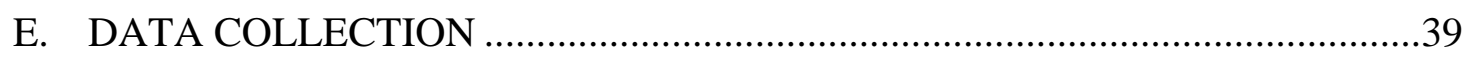

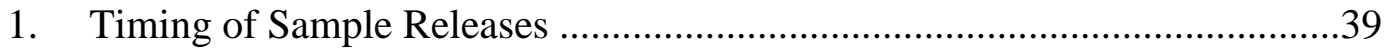

2. Schedule of Contacts to Sample Members ……...........................................40

3. Survey Management Techniques ................................................................42

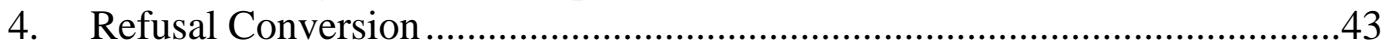

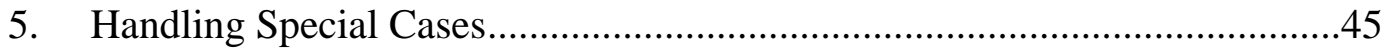

6. Use of Updated D\&B Files ......................................................................4

7. Monitoring and Data Quality .................................................................49 


\section{CONTENTS (continued)}

Chapter

E. (continued)

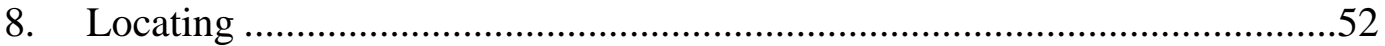

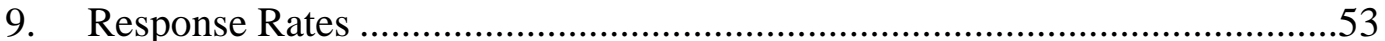

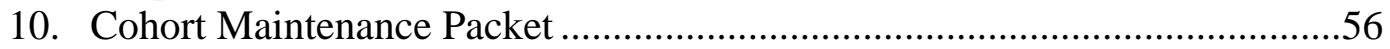

F. CODING AND DATA PROCESSING .......................................................59

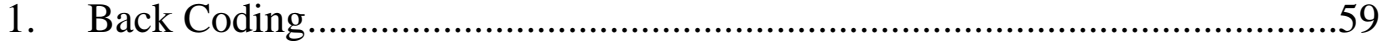

2. Industry Coding ..............................................................................6

3. Financial Data Coding ........................................................................6

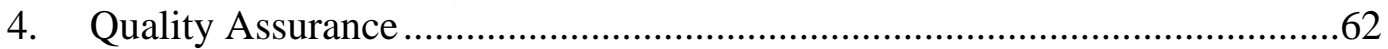

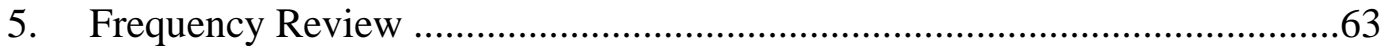

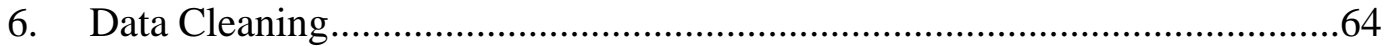

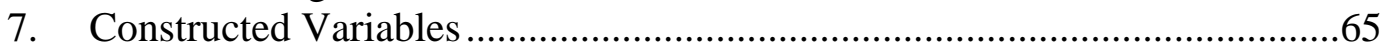

8. Preparation of Codebook and Data Documentation ..................................67

G. WEIGHTING AND NONRESPONSE ADJUSTMENTS .................................67

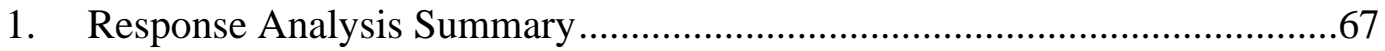

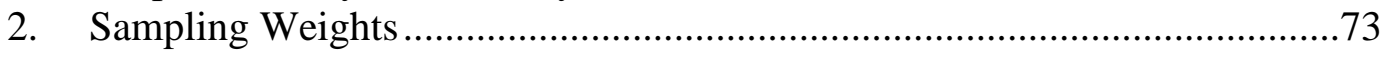

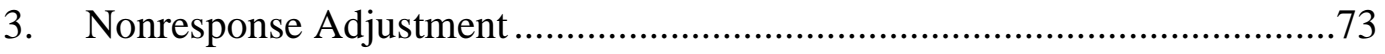

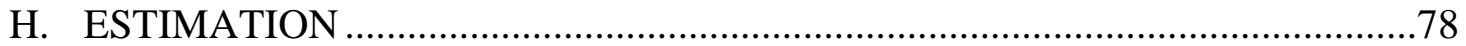

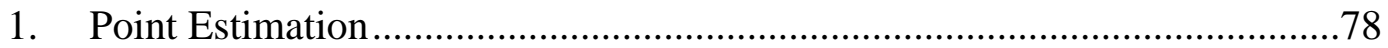

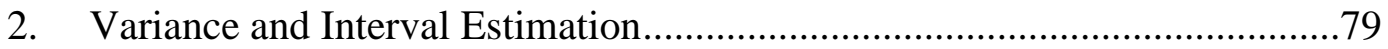

3. Selected Estimates and Variances...............................................................8 80 


\section{LIST OF TABLES}

Table

Page

$1 \quad$ KFS MILESTONES 8

2 TECHNOLOGY SAMPLING STRATA DEFINITIONS 27

3 SAMPLING FRAME OF BUSINESSES IN D\&B DATABASE: BUSINESSES WITH START DATE OF 2004. 29

4 SAMPLING FRAME OF BUSINESSES DECEASED IN D\&B DATABASE: JUNE 2005 TO NOVEMBER 2005, WITH 2004 START DATES

5 D\&B EMPLOYEE COUNT CATEGORIES BY WOMAN-OWNERSHIP AND MAN-OWNERSHIP STATUS AND TECHNOLOGY CLASSIFICATION FOR SAMPLE SELECTION 30

6 SAMPLES FROM JUNE AND NOVEMBER 2005 SAMPLING FRAMES FROM D\&B DATABASE: BUSINESSES WITH 2004 START DATE.

7 KFS BASELINE SURVEY RELEASES . 39

8A THE WEIGHTED AND UNWEIGHTED AAPOR RESPONSE RATES ACROSS TECHNOLOGY SAMPLING STRATA UNDER FIRST ELIGIBILITY DEFINITION

8B THE WEIGHTED AND UNWEIGHTED AAPOR RESPONSE RATES ACROSS TECHNOLOGY SAMPLING STRATA UNDER SECOND ELIGIBILITY DEFINITION 56

9 KAUFFMAN FIRM SURVEY WELCOME PACKET MAILINGS BY DATE........58

10 WEIGHTED LOCATION AND RESPONSE RATES AMONG BUSINESSES

11 WEIGHTED LOCATION AND RESPONSE RATES AMONG BUSINESSES IN THE KAUFFMAN FIRM SURVEY: HIGH-TECH.

12 WEIGHTED LOCATION AND RESPONSE RATES AMONG BUSINESSES IN THE KAUFFMAN FIRM SURVEY: MEDIUM-TECH...

13 WEIGHTED LOCATION AND RESPONSE RATES AMONG BUSINESSES IN THE KAUFFMAN FIRM SURVEY: NON-TECH. 
LIST OF TABLES (continued)

$\begin{array}{ll}\text { TABLE } & \text { PAGE }\end{array}$

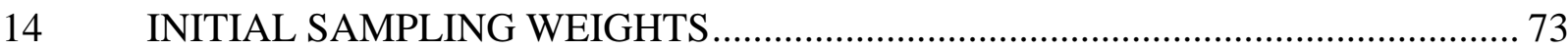

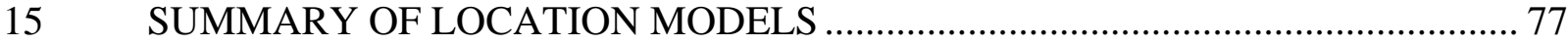

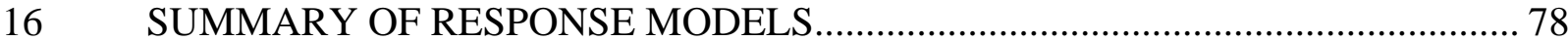

17 VARIANCE ESTIMATION FOR SOME BUSINESS CHARACTERISTICS

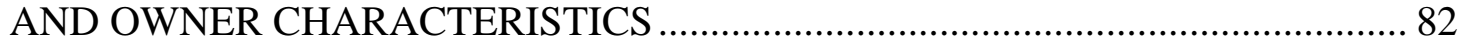




\section{A. EXECUTIVE SUMMARY}

Although entrepreneurial activity is an important part of a capitalist economy, only a small amount of data is available about U.S. businesses in their first years of operation. As part of an effort to gather more data on new businesses in the United States, the Ewing Marion Kauffman Foundation sponsored the Kauffman Firm Survey (KFS), a panel study of new businesses founded in 2004 and tracked over their early years of operation. The Foundation contracted with Mathematica Policy Research, Inc. (MPR) to conduct the KFS, which collects data about the nature of new business formation activity; characteristics of the strategy, offerings, and employment patterns; the nature of the financial and organizational arrangements of these businesses; and the characteristics of their founders.

KFS Design. The study created the panel by using a list frame sample of new businesses selected from the Dun \& Bradstreet (D\&B) Corporation database. For the Baseline Survey, MPR received two sampling frames of businesses started in 2004 from D\&B (in June 2005 and November 2005), totaling roughly 250,000 businesses. In response to the Foundation's interest in understanding the dynamics of high-technology and woman-owned businesses, the sample design for the KFS included allocation across high-technology (based on industry designation) and gender strata. Specifically, the sampling strategy called for 3,000 interviews to be completed in two categories of high-technology businesses and 2,000 interviews to be completed in all other industrial classifications.

Pretesting. MPR conducted extensive questionnaire design to establish consistent definitions of what constituted the start of a new business, as well as to investigate the most efficient methods for collecting these data. The pretesting efforts began with pilot testing business eligibility criteria (Pilot Test 1) using the D\&B sampling frame and convening a technical advisory group to advise on design issues and analytical objectives. During Pilot 
Test 1, we interviewed principals of businesses that started operations in 2003 (according to D\&B). Our experience working with the $\mathrm{D} \& \mathrm{~B}$ database indicated that there is often a time lapse between when businesses start and when D\&B collects information about those businesses. In addition, previous research on new businesses has reported variability in how business founders perceive when their businesses began operations. For these reasons, we asked a series of questions about whether indicators of business activities had occurred and whether the activity was conducted for the first time in 2003. The indicators of business activities included:

- Payment of state unemployment (UI) taxes

- Payment of Federal Insurance Contribution Act (FICA) taxes

- Presence of a legal status for the business

- Use of an Employer Identification Number (EIN)

- Use of Schedule $\mathrm{C}$ to report business income on a personal tax return

To be eligible for the KFS, we assumed that at least one of the activities above had to have been performed in 2003, and none of the activities were performed in a prior year. The results indicated that the incidence of eligible businesses under at least one of these criteria was less than 40 percent. This information helped MPR estimate the resources needed to complete the desired number of interviews in the Baseline Survey.

MPR also conducted a more extensive pilot (Pilot Test 2) to test components of the study design, including instrument length and structure, the use of incentives, and the collection of data through a web survey option with Computer Assisted Telephone Interviewing (CATI) follow-up. The screening criteria tested in Pilot Test 1 were incorporated into the questionnaire used in Pilot Test 2, and MPR developed questions on the other topic areas, including business characteristics, strategy and innovation, business structure and benefits, financing, and demographics of the principals, using a number of previous business surveys (such as the 1992 Economic Census 
conducted by the Census Bureau) as a starting point. We conducted a set of cognitive interviews using the Pilot Test 2 questionnaire, and the questionnaire content was finalized after review and comments from the KFS technical advisory group.

Several findings from Pilot Test 2 were incorporated into the Baseline Survey questionnaire. For example, it was decided that the questionnaire was too long, and that reducing the respondent burden was essential to obtaining a sufficiently high response rate. Analysis of the Pilot Test 2 data by the KFS principal investigator, Dr. Scott Shane, produced a set of recommendations to reduce the questionnaire by roughly one-third. Pilot Test 2 also provided information on an optimal respondent incentive structure to encourage participation in the KFS. We conducted an experiment in Pilot Test 2 to assess four potential incentive strategies: (1) \$1 prepaid and a $\$ 50$ postpaid incentive, (2) \$1 prepaid and no postpaid incentive, (3) no prepaid and a $\$ 50$ postpaid incentive, and (4) no prepaid or postpaid incentive. The results indicated that the $\$ 1$ prepaid incentive had no effect on participation, and that the $\$ 50$ postpaid incentive did. Based on these findings, we offered eligible KFS respondents a $\$ 50$ postpaid incentive for completion of the interview.

Baseline Survey Data Collection. The goal of the Baseline Survey was to interview 5,000 owners of businesses started in 2004. A total of 32,469 selected businesses were released for data collection, which was conducted between July 2005 and July 2006. Similar to Pilot Test 2, a self-administered web survey and CATI were used for the data collection. The MPR project team implemented several comprehensive interviewer training sessions prior to and during the data collection. These training sessions emphasized thorough knowledge of the study and its importance to new business owners, as well as refusal avoidance techniques. The data collection on the Baseline Survey was completed on July 29, 2006 after one full year, with principals of 4,928 businesses being interviewed. When the sampling weights and non-response adjustments 
are applied, this translates to a 43 percent response rate using AAPOR response rate 3. CATI completes accounted for 3,781 (77 percent) and web completes accounted for 1,147 (23 percent) of the total interviews. The results across sampling strata show that 2,034 interviews were completed in the two high-technology strata, and the remaining 2,894 interviews were completed among non-high-tech businesses.

The data collected on the KFS Baseline Survey were processed and then subjected to MPR's quality assurance (QA) procedures. MPR staff reviewed the open-ended responses and back coded responses placed in "Other-Specify" fields that matched one of the prelisted response categories for the question. We also coded the open-ended responses given at the question collecting primary industry of the business using the North American Industry Classification System (NAICS) taxonomy. We reviewed answers to financial questions for consistency and corrected any obvious instances of respondents' double counting of equity or debt amounts. The results of the coding and other data corrections were incorporated into the data file. MPR staff also produced a set of constructed variables, most notably financial measures, for ease of analysis by researchers. Documentation to accompany the data file was produced, including a copy of the questionnaire with related variables listed next to the appropriate questions and a data documentation memo, which listed the origin of variables not found in the questionnaire and a description of the constructed variables.

MPR statisticians produced a set of sampling weights and nonresponse adjustments that were applied to all 32,469 businesses in the KFS Baseline Survey sample. As a result of the oversampling of businesses in high-tech industries, a weighting factor (the inverse of the probability of selection) was required so that estimates collected during the data collection would reflect the true population based on the full D\&B frame. The nonresponse adjustments to the weights were applied to account for those businesses that could not be contacted or interviewed. 
Using logistic propensity modeling and chi-squared automatic interaction detector (CHAID) analysis, MPR statisticians developed these adjustments for the final set of sampling weights. These final sampling weights and adjustments were added to the data file. 


\section{B. THE KAUFFMAN FIRM SURVEY: DESIGN AND PRETESTING}

\section{Introduction}

Entrepreneurship plays a major role in the economic growth of the country, and accurate information about the development and the sustainability of new businesses is essential to developing public and private programs that encourage new business development. However, success in obtaining this information is challenging. Surveys of new businesses tend to be difficult to implement and have typically produced low response rates because of the difficulty of obtaining the cooperation of new business owners. Surveys of new businesses have also faced the complexities of defining what constitutes a new business and when a new business begins operations, events that lend themselves to subjectivity if not carefully defined for business owners. Further, few previous business surveys collected information about the dynamics of business development, since longitudinal surveys of new businesses faced the issue of business attrition. As part of its commitment to advancing entrepreneurship and to the study of new business creation and development, the Ewing Marion Kauffman Foundation sponsored the Kauffman Firm Survey (KFS) to address these informational and methodological gaps related to new business development. The Foundation contracted with Mathematica Policy Research, Inc. (MPR) to conduct the KFS. ${ }^{1}$

\section{Survey Design and Development}

Designing a survey of new businesses is challenging because of the methodological issues related to finding and identifying eligible businesses and developing questionnaire items that accurately measure the key concepts related to business development. The original plan for the

\footnotetext{
${ }^{1}$ The original name for the survey was the Panel Study on New Firms (PSNF). During the survey design and development phase, the PSNF was changed to the Kauffman Firm Survey.
} 
KFS was to assume that businesses listed as having started in the reference year (which was 2004 for the Baseline Survey) in the Dun \& Bradstreet (D\&B) database would be a "new business" eligible for the study. We also assumed that the survey respondent would be a founder or owner of the business who was also involved in business operations, and that the questionnaire items would be similar to those in the 1992 Economic Census. However, as the KFS survey design process evolved, there were multiple changes in the proposed research. The process included a thorough review of new business sampling frame issues, definitions and criteria for what constitutes a new business, identification of priorities for questionnaire items, and a review of data collection techniques to maximize response rates. This introduction provides an overview of the comprehensive and collaborative process that resulted in the KFS. The major milestones during this design phase are summarized in Table 1.

\section{Literature Review and Technical Advisory Group}

The design process began with a literature review and consultation with an advisory group selected by the Foundation (Appendix A). Advisors commented on (1) the definition or criteria for selecting an eligible "new" business; (2) questionnaire items from prior business surveys, in particular the 1992 Economic Census; and (3) new questionnaire items. In total, more than 20 technical advisors contributed to the early development of the KFS. These advisors were selected because of their interest, expertise, and scholarship related to entrepreneurship. In addition, it was expected that the core users of the KFS data files would be among this group, so they were given an opportunity to inform the process. Some advisors were more involved than others. In particular, the Foundation selected a single principal investigator (Dr. Scott Shane) to represent the group and be included in the ongoing work group along with the MPR and Foundation project team. The initial meeting with the advisors to identify and review gaps in currently available information and methodological issues related to new business 
TABLE 1

KFS MILESTONES

\begin{tabular}{|c|c|}
\hline Date & Activity \\
\hline March 2004 & Project awarded to MPR \\
\hline \multirow[t]{2}{*}{ May 2004} & $\begin{array}{l}\text { Initial meeting in Kansas City to review survey objectives and preliminary } \\
\text { design }\end{array}$ \\
\hline & Initial meeting with technical advisors in Washington, DC \\
\hline \multirow[t]{2}{*}{ June 2004} & Principal investigator designated \\
\hline & Received D\&B database \\
\hline \multirow{2}{*}{$\begin{array}{l}\text { June-September } \\
2004\end{array}$} & Developed matrix of questionnaire items \\
\hline & Sample design and questionnaire development \\
\hline \multirow[t]{4}{*}{ August 2004} & Pilot Test $1 \mathrm{~A}$-initial screening criteria \\
\hline & Pilot Test 1B-additional screening criteria \\
\hline & In-person developmental interviews \\
\hline & $\begin{array}{l}\text { Meeting in Washington, DC, to review sample design and questionnaire } \\
\text { development status }\end{array}$ \\
\hline \multirow[t]{2}{*}{ September 2004} & $\begin{array}{l}\text { Questionnaire Review I-Draft of eligibility screening and financial section } \\
\text { of questionnaire sent to technical advisors }\end{array}$ \\
\hline & $\begin{array}{l}\text { Questionnaire Review II-Complete draft questionnaire prepared to send to } \\
\text { technical advisors }\end{array}$ \\
\hline $\begin{array}{l}\text { January-March } \\
2005\end{array}$ & Pilot Test 2-Sample test; full questionnaire test; 400 completed interviews \\
\hline $\begin{array}{l}\text { July } 2005-\text { July } \\
2006\end{array}$ & KFS Baseline data collection; 4,928 completed interviews \\
\hline
\end{tabular}

surveys and their participation in the development of the survey instrument were notable contributions to the KFS.

\section{Initial Advisory Committee Meeting}

To begin the KFS development and design process, an initial meeting in May 2004 was held with a core group of technical advisors selected by the Foundation. The agenda for this meeting 
included (1) an overview of the proposed research design and survey development process; (2) a discussion of the project objectives, including a review of other Foundation entrepreneurship initiatives; and (3) a review of conceptual issues related to new business research, including operational definitions, target population and sampling frame, subpopulations of interest, and questionnaire topics. These discussions resulted in agreement to use the following concepts to frame the development of the KFS: (1) the data collected would be relevant to a "pure" cohort of businesses that started in a single targeted year (2003 for Pilot Test 2, 2004 for the Baseline Survey); (2) the business-not any individual owner or founder-is the focus of the information being collected; (3) financial information related to business formation is the main analytic objective; and (4) a longitudinal survey design was needed to inform an understanding of business development dynamics.

At the very beginning of the project, meetings with the Foundation and the advisory group resulted in discussions of key topics areas to include in the survey and other informational and methodological gaps to consider in the KFS design. To inform this process, MPR conducted a literature review that included about 60 articles and related surveys that focused on business statistics and the dynamics of business formation. In particular, we reviewed the survey instruments used for the 1992 Economic Census, the 1998 Survey of Small Business Finance, and the Panel Study of Entrepreneurial Dynamics. Also, the technical advisory group outlined a survey "wish list" that would best meet the needs of academic researchers, government agencies, and public policy decision makers who would use the KFS data. ${ }^{2}$ The original advisory group, supplemented with additional participants at various phases of the survey development,

${ }^{2}$ During the same time period as the KFS development, the Foundation was also funding a major effort by the National Academies of Science (NAS) to identify the information needs related to business surveys and other information needed to study new business development. Several NAS participants were also KFS advisors. 
continued to provide comments and suggestions to assist in crafting the questionnaire and responding to methodological questions that surfaced. In addition, the Foundation selected a principal investigator (Dr. Scott Shane) to represent the advisors and be a single point of contact for ongoing discussions and decisions that informed the development of the sample and questionnaire design.

\section{Pilot Test 1}

Prior to work on the content areas of the KFS questionnaire, there was a need to understand how well the definitions of a new business as envisioned by the Foundation and the technical advisory group matched up with the sample frame from D\&B. Discussion between the Foundation, MPR, the principal investigator, and the technical advisory group about possible criteria that could be used in the survey to identify eligible businesses in the D\&B sample frame resulted in the decision to conduct pilot testing on these criteria prior to beginning the Baseline Survey. The resulting pilot test (Pilot Test 1) focused on determining the likely eligibility of businesses in the D\&B sample based on these criteria and learning more about the performance and quality of the D\&B sample, specifically the reliability of the business owner gender variable for sampling purposes.

Pilot Test 1 consisted of two different eligibility screening tests-Pilot Test 1A and Pilot Test 1B. Pilot Test 1A was conducted in August 2004 and was performed to test the incidence of state unemployment insurance (UI) and Federal Insurance Contributions Act (FICA) tax payments among the D\&B sample. A small sample of businesses (720) was selected from the 2003 D\&B file in July 2004, and the principals of these businesses were contacted to answer a few questions (the questionnaire is included as Appendix B). Interviews were completed with 173 of the selected businesses. For the two business operations criteria (UI and FICA), we asked the principals whether or not the business had made these payments, and for those businesses 
reporting that they did, whether 2003 was the first year these payments were made. The main finding from Pilot Test 1 was that 20 percent of businesses reported making either UI or FICA payments during the reference year of 2003, which was far lower than expected.

The Pilot Test 1A results led to suggestions to expand the eligibility criteria. The project team was concerned about using UI and FICA payments exclusively, since these measures are driven by employment and would cause underrepresentation of nonemployer, single-owner businesses. The information from the business survey literature and from members of the technical advisory group indicated that a sizeable minority of new businesses have no employees, and not capturing enough of such businesses would increase bias in the survey estimates. To test additional eligibility criteria, Pilot Test $1 \mathrm{~B}$ contacted the same businesses as in Pilot Test 1A but included questions about legal business status (sole proprietorship, general partnership, limited partnership, C-corporation, subchapter S-corporation, limited liability company), acquisition of an Employer Identification Number (EIN), and use of an Internal Revenue Service Schedule C or C-EZ as part of the owner's 2003 income tax return. The questionnaire for Pilot Test $1 \mathrm{~B}$ is included in Appendix C. The eligibility criteria tested in Pilot Tests $1 \mathrm{~A}$ and $1 \mathrm{~B}$ were incorporated into the KFS questionnaire.

\section{Questionnaire Development}

The draft KFS questionnaire was developed prior to a second and more extensive pilot test (Pilot Test 2), using the matrix of topics suggested by the academic advisors and relevant questionnaire items from previously conducted studies. An operational goal suggested by the advisors during the design process was harmonization of the KFS with other similar surveys. Using the items included in this initial draft, we conducted important discussions about the analytic contribution of the KFS to the field of entrepreneurship studies. The process was 
thorough and included a Delphi-type approach ${ }^{3}$ to document advisor questionnaire item recommendations. The project team carefully assessed the advisors' suggestions and responded with complete documentation on the rationale for KFS inclusion or exclusion. The memo containing the comments and decisions is included in Appendix D of this report. At the conclusion of Pilot Test 2, the data were provided to selected members of the technical advisory group (including the Principal Investigator, Dr. Scott Shane) for analysis. The analysis conducted using these data was used to evaluate questionnaire items and aided decisions on which questions to include in the Baseline Survey instrument.

\section{Cognitive Interviews}

During the development of the KFS questionnaire, in-person cognitive interviews were conducted with eligible new business owners to assist in evaluating the survey instrument. Cognitive interviews are conducted to identify difficulties in question comprehension, perceptions of the response task, memory recall strategies used by respondents, difficulties in selecting a response choice, interpretations of question reference periods, and reactions to sensitive questions. Six in-person interviews were conducted with individuals who started businesses in 2003. The convenience sample of business owners was recruited by contacting New Jersey associations that support the development of new businesses.

The cognitive interviews were conducted to better understand the respondent burden involved with completing the questionnaire and how business owners would respond to potentially sensitive business financial questions. Also, key concepts used in the questionnaire were reviewed to make sure they were understood. For example, the cognitive interviews

\footnotetext{
${ }^{3}$ The Delphi approach seeks consensus by solicitation and comparison of the views of experts. In the KFS, the questionnaire was provided to members of the technical advisory group, and the comments from each member were evaluated independently before grouping comments on particular questions.
} 
assessed if business owners can report accurately when they are asked to retrieve information for the reference periods "in calendar year 2003" or "on December 31, 2003." The cognitive interviews provided a number of suggestions about how business terms included in the questionnaire could be better defined for the new business population, which were incorporated into the questionnaire prior to Pilot Test 2.

\section{8. $\quad$ Pilot Test 2}

The information from Pilot Test 1 , as well as the desire to test the questionnaire fully resulted in the recommendation for additional testing (Pilot Test 2) prior to conducting the KFS Baseline Survey. In addition to the eligibility criteria tested in Pilot Test 1, another screening criterion was tested in Pilot Test 2 to restrict businesses that were inherited, subsidiaries of existing businesses, and nonprofit organizations. In addition to testing the length of questionnaire administration, Pilot Test 2 allowed the project team to review response distributions, as well as the prevalence of missing and inappropriately skipped questions and incomplete questionnaires. The Pilot Test 2 questionnaire is included in Appendix E.

Pilot Test 2 was conducted from January 2005 to March 2005, among a sample of 6,235 businesses selected from the 2003 D\&B frame of business starts. We completed 400 interviews during Pilot Test 2, and a total of 745 businesses were screened out as ineligible, either by completing the screening questions through the web survey or by CATI. About 710 cases refused to participate, with most refusing before participating in the screener. Pilot Test 2 produced a lower level of response than expected, and a number of the decisions made prior to the Baseline Survey were driven by the desire to increase response and lower the cost of completing interviews.

Pilot Test 2 also provided an opportunity to conduct experiments on methodological approaches that could be used to improve the quality of data collection-in particular, new 
businesses' participation in the survey. The survey research literature strongly suggests that participant incentives can increase participation, so we expected that offering incentives to Pilot Test 2 sample members would increase participation. To better inform the decision of whether to offer an incentive and how it should be offered to sample members, we conducted an experiment during Pilot Test 2 with four types of incentives: (1) $\$ 1$ prepaid and a $\$ 50$ postpaid incentive, (2) \$1 prepaid and no $\$ 50$ postpaid incentive, (3) no prepaid and a $\$ 50$ postpaid incentive, and (4) no prepaid or postpaid incentive. Each group was analyzed to identify the most cost-effective incentive approach for the full KFS.

Another Pilot Test 2 experiment was the use of two different methods of data collection-a self-administered web questionnaire and a telephone interview. We used a "forced-web" approach in which the advance materials mentioned only the web survey, since having sample members respond using the web questionnaire is the most cost-effective method to obtain information. This approach encourages responding through the web survey because the advance materials did not mention telephone followup. Using this method assisted in estimating the expected number of completed interviews using the web questionnaire, which was useful in preparing for the Baseline Survey. It also provided information to compare the two methods of data collection and assess possible mode effects on data quality.

Based on the results of Pilot Test 2, several decisions were made prior to beginning the KFS Baseline Survey. In particular, the length of the questionnaire was reduced. The questionnaire averaged 50 minutes to complete by telephone, which was found to be a substantial time commitment from new business owners. Shortening the questionnaire accomplished two objectives: (1) focusing on the financial items that were the main analytic priority and (2) reducing the length of time to complete the questionnaire to encourage participation and increase the response rate. 
Based on the incentive experiment, it was decided to only use a $\$ 50$ postinterview payment, and no prepaid incentive. There was no statistical difference between the prepayment incentive groups in terms of completion. There was also no statistical difference in completions among the postpayment groups, although there is evidence of a directional effect ( 7.5 percent completed the interview among the incentive treatment group versus 5.4 percent in the control group). Given the expected difficulty of obtaining a high response rate during the Baseline Survey, it was decided that offering the incentive would be more cost-effective than additional followup to nonresponding businesses.

\section{Screener and Questionnaire Content}

Based on the cognitive interviews, comments provided by the technical advisory group, and lessons learned from Pilot Test 2, the content of the KFS Baseline Survey questionnaire was finalized in June 2005. The first two sections of the questionnaire were devoted to screening for an appropriate respondent and to ensuring that the business was eligible for the survey. The remaining sections covered business characteristics, strategy and innovation, business organization and employee benefits, business finance, and work behaviors and demographics of the owners. All of these topics are discussed in greater detail next.

Section A: Introduction. This section introduced the study, the sponsor, and MPR as the organization conducting the study. It also verified that the correct business was reached and that it was still in operation. Section A also ensured that the person listed by D\&B as the business principal was an owner, an operator, and a founder of the business. Because of the types of detailed questions on the financial situation of the business asked in the KFS Baseline Survey, it was important to identify a person who would be knowledgeable enough to give accurate information on the business. Therefore, this part of the screener identified a founder and current owner of the business who was also involved in the business's day-to-day operations. Finally, 
the business address was confirmed. If the business had ceased operations, the reason for the closing of the business was collected.

Section B: Eligibility Screening. Section B was the screener for business eligibility. This section also captured the way the business originated. Examples include a new business started by one or more individuals and the purchase of an existing business or franchise. Businesses that were inherited from someone else, were set up as a subsidiary of an existing business, or created as a not-for-profit organization are examples of businesses that did not qualify and were screened out.

The business eligibility screener also ensured that the business qualified based on the start of business operations in 2004. As discussed earlier, the KFS team worked to develop a set of screening criteria that would be comprehensive enough to include all selected businesses that began operations during the reference year of 2004. This section contained the following screening criteria:

- Type of Business Start. The way that the business started can indicate whether or not the business began in 2004. Businesses that were inherited, wholly owned by another business, or were established as not-for-profit organizations were excluded using this measure.

- Legal Status. Respondents were asked the legal status of the business as of the reference date of December 31, 2004. Having a valid business legal status (sole proprietorship, limited liability company, subchapter S corporation, C-corporation, general partnership, limited partnership) was an indicator of business activity.

- Employer Identification Number. The acquisition of an EIN during 2004 was another indicator we used to distinguish when the business was formally established. Meeting this criterion would mean that the business went through the process of filing all the necessary documentation with the government to have the business recognized as an independent entity. Those acquiring an EIN prior to 2004 were excluded using this measure.

- Schedule C or Schedule C-EZ. Businesses reported by principals to be organized as sole proprietorships were asked if they used a Schedule C or Schedule C-EZ to report business income on a personal income tax return. Those reporting that they had used 
this method were then asked if 2004 was the first tax year they used it, with those responding that 2004 was not the first year being excluded.

- State Unemployment Insurance Payments. As mentioned earlier, businesses making UI payments for the first time in 2004 were eligible for the survey. Those making UI payments prior to 2004 were excluded.

- Federal Insurance Contribution Act Payments. As mentioned earlier, businesses making FICA payments for the first time in 2004 were eligible for the survey. Those making FICA payments prior to 2004 were excluded.

In order to be eligible for the KFS, businesses had to have at least one of these activities occur for the first time in 2004, and none of the activities could have taken place before 2004.

Section C: Business Characteristics. Once a business was determined to be eligible for the study, respondents provided information about the nature of the business in this section. The respondent was asked to confirm the description of the industry in which the business operates (based on the D\&B data). If the description was incorrect, the respondent was asked to provide an updated description of the business's primary industry. Other information collected in this section included the names of other owner-operators and the number of employees the business had on both a full- and part-time basis. This section ended by asking about the type of location from which the business operates.

Section D: Strategy and Innovation. This section included questions about whether the business offered a product or a service; whether the respondent believed that the business had a competitive advantage; and whether the business owned or licensed any intellectual properties, such as patents, copyrights, or trademarks. Respondents were also asked if the business had any sales during 2004 and the percentage distribution of such sales to individuals, government, and other businesses.

Section E: Business Organization and Human Resource Benefits. This section included questions about the number of employees who performed various functions within the business 
and the types of benefits offered to employees. The benefit questions were asked separately for full-time and part-time employees.

Section F: Business Finances. The business finances section was the main focus of the questionnaire. Topics covered in this section included:

- Equity investment by owners into the business in 2004

- Percentage of ownership by each owner for multiple-owner businesses

- Sources and amount of debt financing by the business and its owners

- Amount of revenue, if any, the business received in 2004

- Total expenses incurred by the business in 2004

- Total expenses spent on salary and wages

- Profit or loss during 2004

- Types of assets and liabilities and their individual estimated value

Section G: Work Behaviors and Demographics of Owner(s). This section collected demographic and other information on the owner-operators of the business. Respondents were asked if they were paid employees of the business and how many hours they worked at the business in an average week. They were also asked how many years of experience they had in the industry of the new business and if they had started other new businesses. The rest of this section collected basic demographic characteristics on the owner-operators, such as age, gender, race, education level, and U.S. citizenship. For multiple-owner businesses, respondents were asked these questions about themselves and then about each of the other owner-operators.

Finally, contact information was collected for the follow-up surveys. This information included a name, address, phone number, and email address of someone to contact if we were unable to reach the business for a follow-up study. It also asked for an email address of the respondent and a website for the business. The name and address of the person to whom the 
incentive check would be sent was also recorded. At the conclusion of the interview, the respondent was thanked and told the incentive check would be sent within two to three weeks. The final Baseline Survey questionnaire is included in Appendix F.

\section{Instrument Development and Testing}

Development of the Baseline web and CATI instruments began during Pilot Test 2. As mentioned earlier, the length of the Pilot 2 instrument was determined to be too long, requiring some questions to be deleted or simplified. After these changes were made, testing of the CATI and web instruments began. Test case IDs were made available to project staff members, who developed scenarios in order to check programming logic paths, edit checks, question wording, and formatting. Testers also ensured that partially completed web cases would route to the next unanswered question upon reentry to the survey by either web or CATI. They also tested that a completed case, in either web or in CATI, could not be reentered in the other mode.

Testing of the programming logic for eligibility of both the owner and the business was rigorous. In both CATI and web versions, the program had to ensure that the respondent to the survey was an owner, an operator, and a founder of the business. In addition, because of the stringent standards set up for qualification of a business, multiple scenarios had to be tested to ensure that only businesses that started in 2004 qualified to complete the instrument. The program also had to allow both the owner's name or business's name to be corrected. Finally, paths had to be set up and tested to cover situations in which one or more owners of the business did not qualify as an owner-operator-founder, in order to allow the interviewer to screen for another owner qualified to respond to the study.

The testing of the web and CATI surveys took place simultaneously, with similar programming logic and edit checks outlined earlier in CATI also done for the web instrument. Consistency between the modes was an important goal. Minor wording changes (phrases 
included in the CATI instrument such as "Now I am going to ask you..." were eliminated in the web instrument), and minor differences in answer formats were the only differences in format between the two instruments. As discussed in more detail later, edit checks in web and CATI were structured differently, because of the presence of a telephone interviewer who could probe and follow up on inconsistent answers in the CATI version.

Prior to the start of data collection, a comprehensive test of systems was conducted. A set of 200 test cases was used to test the interaction between the web and CATI surveys and the Survey Management System (SMS). Items tested included proper transfer of contact information to the SMS for locating cases; proper tracking of cases; proper routing of cases to specific interviewers; updates of name, phone, and address changes; and re-statusing of cases. A number of problems were identified and corrected before the beginning of actual data collection, thus making the initial data collection more efficient.

\section{a. Web}

Any web instrument needs to allow easy access and efficient collection of data and needs to assure respondents that their information will be kept confidential. Because the Baseline web respondent would not have the aid of a telephone interviewer, the web survey also had to provide instructions and help within the instrument itself. The first few screens of the instrument contained information on usability and provided instructions on filling out the web survey. The login screen for the web survey had the Kauffman Foundation name and logo, a welcome to the KFS, and instructions to contact the help desk via email or a toll-free telephone number. After respondents entered the login and password, they would see an introduction screen, which included information about the purpose of the survey, the role of the Kauffman Foundation, the promise of the $\$ 50$ incentive for completing the survey, and an assurance of confidentiality. 
Also included in the introduction screen were links to additional information about completing the survey and access to FAQs.

The next screen provided respondents with some basic instructions and information, such as how to leave or "suspend" the instrument if necessary and how to return to the instrument when they had the time to finish. The screen also informed respondents that all questions should be answered in the order presented, and that the survey would automatically suspend if no answer was entered over a period of 30 minutes, at which point they would have to log in again in order to resume the survey.

Providing the web respondent sufficient help to get started was one goal of designing the web survey. Another was to structure the web instrument to minimize the burden for the respondent. Whenever possible, two or more related questions were programmed onto one web screen to enable the respondent to answer multiple questions without going from screen to screen. This reduced the interview time for the respondent and streamlined the look of the survey. The respondent could back up to a previous screen with a "back" button, move on to the next screen via a "next" button, or suspend the instrument. Links to both the FAQs and instructions screens were available throughout the survey. Upon completion of the web instrument, the sample member was thanked and given a link to the Kauffman Foundation website for additional information about the Foundation.

Another goal of the web design was to inform a web respondent that he or she had entered inconsistent information or information that appeared to be incorrect. Edit checks in web instruments are a balancing act between the need for complete data and the risk of alienating web respondents. An edit check is an attempt to obtain an answer (if a field is left blank) or resolve an inconsistency. For example, if a respondent says his or her business has five employees but then says that four are full-time and two are part-time, the screen with the original answer 
appears, with a message indicating that the sum of full-time and part-time employees does not add up to the total number of employees. The web version did allow respondents to leave answers blank and did not explicitly give "don't know" and "refuse" response categories.

Because the qualification of the owner and the business was vital to the study, edit checks on the web for these questions were the same as those in CATI. This assured that web respondents met the same rigorous qualification for participation as did CATI respondents. For other parts of the survey, however, fewer edit checks were included in order to reduce the web respondents' burden and to encourage web respondents to complete the questionnaire. Skipping financial amount questions did bring up the same dollar ranges as in CATI, in order to encourage an estimate of the financial amount.

\section{b. CATI}

Because a telephone interviewer is available to probe and follow up on answers in the CATI version, no blank answers are allowed in the CATI version. If the respondent refuses to answer a particular question, the CATI interviewer indicates a refusal and a similar option is available in CATI for a "don't know" response. The screen format of the CATI instrument is designed for the telephone interviewer, not the respondent. The CATI instrument has far more screens than the web instrument, because the purpose is to make each question easily readable to the interviewer, instead of putting multiple questions on the same screen for the web respondent's convenience. Probes and interviewer instructions are formatted in a different way than text that is required to be read verbatim, in order to aid the interviewer in easily identifying what should and should not be read. 


\section{SAMPLING DESIGN}

\section{Target and Study Population}

The target population is the population on which conclusions are drawn. For KFS, the target population was all new businesses that were started in the 2004 calendar year in the United States (the 50 states plus the District of Columbia). The target population excludes any branch or subsidiary owned by an existing business or a business inherited from someone else. The issue that arose immediately with this target definition is the meaning of "started." As noted in the previous section, MPR worked with the Ewing Marion Kauffman Foundation and the technical advisory group to evaluate alternative definitions of "started" through the pilot tests based on indicators of business operations, such as having an employer identification number, schedule $\mathrm{C}$ income, or a legal form for the business or having paid state unemployment insurance (UI) or Federal Insurance Contribution Act (FICA) taxes. For the study population, a business starting in 2004 was defined as one of the following:

- A new, independent business that was created by a single person or a team of people

- The purchase of an existing business

- The purchase of a franchise

Businesses were excluded if they had an EIN, Schedule C income, a legal form, or if they paid state UI or FICA taxes prior to 2004.

The study population was further defined by the sampling frame source, D\&B. Newly formed businesses are particularly difficult to identify because there is no single registry of new businesses, and the time between establishing the business and the business showing up in telephone or business directories may be six months or more. The Census Bureau and the Bureau of Labor Statistics maintain lists of businesses and employers, but these lists also suffer 
from a similar time lag and are not available for use by those outside of their respective organizations. We chose the D\&B database as the sampling frame source because it is one of the largest commercial lists available, and $\mathrm{D} \& \mathrm{~B}$ offers information on linkages among establishments within enterprises (or businesses). The $\mathrm{D} \& \mathrm{~B}$ database is a compilation of data from various sources, including credit bureaus, state offices where new businesses are registered, and companies (such as credit card and shipping companies) that all businesses are likely to use. However, using the $\mathrm{D} \& \mathrm{~B}$ database imposed limitations on the study population because we relied on the D\&B reported year of the start of the business. We included all businesses for which D\&B reported a start date of 2004 in the sampling frame. If the business was selected from the sampling frame, we screened the business for eligibility (as described above). If the data element for the start year was left blank or was miscoded in error to some other year than 2004, a business that started in 2004 based on the other criteria had no chance of entering the study population or sampling frame. The coverage of the target population of businesses is constricted by the correctness of the business's start date in the D\&B database.

\section{Sample Stratification}

As discussed above, we chose the D\&B database as the sampling frame because its system of corporate linkages allowed us to restrict the sampling frame to businesses (or enterprise units) that started in 2004 by excluding new branches, intermediary units (such as regional headquarters of a business), or subsidiaries formed in 2004. We then partitioned the D\&B database into six sampling strata defined by industrial technology categories (based on industry designation) and gender of the owner or CEO of the business (based on the D\&B data element and additional information discussed later). The purpose of the strata based on the industrial technology categories was to allow for a larger sample allocation among new businesses in the high-technology fields because of high interest in these industries. The second stratification 
factor (gender of the owner or CEO of the business) was to ensure proportional representation from woman-owned businesses, although woman-owned businesses were not oversampled.

The high-technology sampling strata were defined based on categorization developed by Hadlock, Hecker, and Gannon (1991) ${ }^{4}$ from the Bureau of Labor Statistics (BLS). They defined "high technology" based on an industry's percentage of research and development (R\&D) employment, which is defined as the "number of workers who spend the majority of their time in R\&D.” Data on R\&D employment were derived from the BLS Occupational Employment Statistics program and were based on industries classified at the three-digit level Standard Industry Classification (SIC) code. Industries whose proportion of R\&D employment is at least equal to the average proportion for all industries were then identified as high-technology industries. Among the businesses classified as high technology, we looked further into their twodigit level or three-digit level SIC codes. Using the initial definition of a high-technology business, the SIC codes, and discussion with the technical advisory group, the businesses in the sampling frame were further classified as high-tech or medium-tech. ${ }^{5}$ The final classifications of technology businesses were:

- High-Tech. Chemicals and allied products, industrial machinery and equipment, electrical and electronic equipment, instruments and related products

- Medium-Tech. Other industries that meet the R\&D criteria by the BLS, although a lower percentage of $R \& D$ employment than in the high-tech group

- Non-Tech. All industries not included in the R\&D criteria

\footnotetext{
${ }^{4}$ Paul Hadlock, Daniel Hecker, and Joseph Gannon, "High Technology Employment: Another View." Monthly Labor Review (July 1991): 26-30.

${ }^{5}$ These classifications by technology status were designed to help identify businesses that could be considered as falling into a particular category, such as high-technology business. The technology sampling strata are not designed for use as analysis groupings.
} 
The sampling design called for 3,000 interviews to be completed in two categories (hightech and medium-tech) of technology businesses and 2,000 interviews to be completed in all other industrial classifications. The industries in the technology sampling strata are shown in Table 2.

The woman-owned indicator in the D\&B database is a code indicating that a woman owns the majority of the business. This information is collected via voluntary filings with the Small Business Administration (SBA), third-party sources, and internal D\&B investigations and through the use of $\mathrm{D} \& \mathrm{~B}$ algorithms designed to identify proprietorships that have a CEO with a female name. For some businesses, there was not enough information to tell whether or not it was woman-owned. In addition to the $\mathrm{D} \& \mathrm{~B}$ indicator, we also reviewed the name of the CEO or owner reported by D\&B. If the name seemed to be a woman's name or the prefix was "Ms.," "Mrs.," or "Miss," we classified the business as woman-owned. We tested the accuracy of the woman-owned indicator on a sample of businesses during Pilot Test 1, and it was shown to be accurate in 85 percent of the businesses in identifying woman-owned businesses.

\section{Sample Frame}

Compiling information on newly formed businesses is particularly difficult because the time between establishing the business and the business appearing in one of D\&B's sources may be six months or more. For the KFS Baseline Survey, we were interesting in capturing as complete a picture of businesses starting in 2004 as possible, so we arranged with D\&B to provide multiple files at different time points during 2005. We obtained an initial file in June 2005 and a second file in November 2005. As shown in Table 3, the June 2005 file contained 188,292 businesses with the starting year of 2004. This number was approximately 30 percent lower than a similar file received in June 2004 of businesses starting in 2003, which was used to draw the 
TABLE 2

TECHNOLOGY SAMPLING STRATA DEFINITIONS

\begin{tabular}{lcl}
\hline Technology Sampling & & \\
Stratum & SIC Code & Industry \\
\hline \multirow{1}{1}{ (High) } & 28 & Chemicals and allied products \\
& 35 & Industrial machinery and equipment \\
& 36 & Electrical and electronic equipment \\
2 (Medium) & 38 & Instruments and related products \\
& 131 & Crude petroleum and natural gas operations \\
& 211 & Cigarettes \\
& 229 & Miscellaneous textile goods \\
& 261 & Pulp mills \\
& 267 & Miscellaneous converted paper products \\
& 291 & Petroleum refining \\
& 299 & Miscellaneous petroleum and coal products \\
& 335 & Nonferrous rolling and drawing \\
& 348 & Ordnance and accessories, not elsewhere classified \\
& 371 & Motor vehicles and equipment \\
& 372 & Aircraft and parts \\
& 376 & Guided missiles, space vehicles, parts \\
& 379 & Miscellaneous transportation equipment \\
737 & Computer and data processing services \\
871 & Engineering and architectural services \\
& 873 & Research and testing services \\
& 874 & Management and public relations \\
& 899 & Services, not elsewhere classified \\
& \\
& All other industries \\
\hline & & \\
& &
\end{tabular}

Pilot Test 2 sample. We investigated the lower number and could find no clear changes in operations by $\mathrm{D} \& \mathrm{~B}$ and no evidence from federal sources to explain this drop. The November 2005 D\&B file included 62,990 additional businesses with start dates in 2004, resulting in a total pool of 251,282 businesses from the combined June and November files (Table 3). However, 13,439 businesses from the June 2005 file ( 7 percent) were not in the November file (see 
Table 4) and were presumed to be deceased or no longer in business, which left 237,843 businesses in the combined database.

\section{Sample Selection and Release}

We received two frame files from D\&B, one in June 2005 and the other in November 2005, and we balanced the sample size between the two files to reduce unequal sampling weights. Because the businesses in the high-technology sampling stratum numbered only 3,725 (again fewer than expected), and we wanted a large pool of these businesses for the longitudinal panel, we decided to include all of them in the sample in order to obtain an adequate count of these businesses. For the other strata, we were somewhat conservative but still released relatively large samples.

To draw the sample for data collection, we needed a sufficiently large sample size to accommodate the expected low eligibility rate, and we also wanted a sufficient reserve to allow for quick release of additional sample as needed. Based on the results of Pilot Test 2, we assumed a 40 percent response rate and a 40 percent eligibility rate. However, because we were uncertain about these rates, we also wanted a 100 percent reserve sample.

Sampling selection was done using Chromy's sequential random sampling method. ${ }^{6}$ This method selects units sequentially with equal probability and without replacement. Before the sample was drawn, businesses within each technology and woman-owned indicator sampling stratum were sorted by two control variables: (1) D\&B employee count categories, and (2) three-digit zip code. Table 5 shows D\&B employee count categories. The implicit stratification

${ }^{6}$ J. R. Chromy, "Sequential Sample Selection Method." Proceedings of the American Statistical Association, Survey Research Methods Section (1979), 401-406. 
TABLE 3

\section{SAMPLING FRAME OF BUSINESSES IN D\&B DATABASE: BUSINESSES WITH START DATE OF 2004}

\begin{tabular}{|c|c|c|c|c|c|c|}
\hline $\begin{array}{l}\text { Technology } \\
\text { Sampling Strata }\end{array}$ & $\begin{array}{c}\text { Woman } \\
\text { Ownership } \\
\text { Sampling } \\
\text { Strata }\end{array}$ & $\begin{array}{l}\text { June } \\
\text { File }\end{array}$ & $\begin{array}{l}\text { Deceased in } \\
\text { November }^{\mathrm{a}}\end{array}$ & $\begin{array}{l}\text { New in } \\
\text { November }\end{array}$ & $\begin{array}{l}\text { Total (June and } \\
\text { November) }\end{array}$ & $\begin{array}{c}\text { Operating } \\
\text { Total }\end{array}$ \\
\hline \multirow[t]{3}{*}{ High-Tech } & & 2,593 & 144 & 1,276 & 3,869 & 3,725 \\
\hline & Yes & 361 & 21 & 166 & 527 & 506 \\
\hline & No & 2,232 & 123 & 1,110 & 3,342 & 3,219 \\
\hline \multirow{3}{*}{ Medium-Tech } & & 22,544 & 926 & 7,117 & 29,661 & 28,735 \\
\hline & Yes & 4,332 & 153 & 1,215 & 5,547 & 5,394 \\
\hline & No & 18,212 & 773 & 5,902 & 24,114 & 23,341 \\
\hline \multirow[t]{3}{*}{ Non-Tech } & & 163,155 & 12,369 & 54,597 & 217,752 & 205,383 \\
\hline & Yes & 32,016 & 2,177 & 9,951 & 41,967 & 39,790 \\
\hline & No & 131,139 & 10,192 & 44,646 & 175,785 & 165,593 \\
\hline Total & & 188,292 & 13,439 & 62,990 & 251,282 & 237,843 \\
\hline
\end{tabular}

${ }^{a}$ Deceased in November is the count of enterprises in the D\&B database in June 2005 that were not in the database in November 2005.

TABLE 4

SAMPLING FRAME OF BUSINESSES DECEASED IN D\&B DATABASE: JUNE 2005 TO NOVEMBER 2005, WITH 2004 START DATES

\begin{tabular}{lcrcc}
\hline $\begin{array}{l}\text { Technology } \\
\text { Sampling Strata }\end{array}$ & Woman-Ownership & & \\
\hline High-Tech & Sampling Strata & June File & Deceased $^{\text {a }}$ & Percent Deceased \\
& Yes & 2,593 & 144 & 5.6 \\
& No & 361 & 21 & 5.8 \\
Medium-Tech & & 2,232 & 123 & 5.5 \\
& & & \\
& Yes & 22,544 & 926 & 4.1 \\
Non-Tech & No & 18,332 & 153 & 3.5 \\
& & & 773 & 4.2 \\
& & 163,155 & 12,369 & 7.6 \\
Total & Yes & 32,016 & 2,177 & 6.8 \\
\hline
\end{tabular}

${ }^{\mathrm{a}}$ Deceased in November is the count of enterprises in the D\&B database in June 2005 that were not in the database in November 2005. 
TABLE 5

\section{D\&B EMPLOYEE COUNT CATEGORIES BY WOMAN-OWNERSHIP AND MAN-OWNERSHIP STATUS AND TECHNOLOGY CLASSIFICATION FOR SAMPLE SELECTION}

\begin{tabular}{lcc}
\hline $\begin{array}{l}\text { Technology Sampling } \\
\text { Strata }\end{array}$ & $\begin{array}{c}\text { Woman-Ownership Sampling } \\
\text { Strata }\end{array}$ & Man-Ownership Sampling Strata \\
\hline High-Tech & $0-1,2-5,5+$ & $0-1,2-4,5-9,10+$ \\
Medium-Tech & $0-1,2-4,5-9,10+$ & $0-1,2-4,5-9,10+$ \\
Non-Tech & $0-1,2-4,5-9,10+$ & $0,1,2-4,5-9,10+$ \\
\hline
\end{tabular}

was included so that the sample had the same distributions on control variables as found in the sampling frame.

After the sample was drawn, it was randomly divided into waves within each technology sampling stratum, with each wave containing 10 (or in some cases 9) businesses. Each wave was constructed such that a similar distribution was present on key variables, such as woman-owned indicator and employee size, as in the whole sample. Instead of being released all at the same time, the sample was released in waves, independently within each high-technology sampling stratum, until the target sample size was achieved. Using this process, data collection is more organized, since a relatively smaller sample size is worked on at any time, and more economical, since not all of the waves need to be released to reach the target sample size. Table 6 shows the final sample size and sampling rates to achieve the target number of completes $(5,000)$. 
TABLE 6

SAMPLES FROM JUNE AND NOVEMBER 2005 SAMPLING FRAMES FROM D\&B DATABASE: BUSINESSES WITH 2004 START DATE

\begin{tabular}{|c|c|c|c|c|c|c|}
\hline $\begin{array}{l}\text { Technology } \\
\text { Sampling } \\
\text { Strata }\end{array}$ & $\begin{array}{c}\text { Woman- } \\
\text { Ownership } \\
\text { Sampling } \\
\text { Strata }\end{array}$ & $\begin{array}{c}\text { June } \\
\text { Sample }\end{array}$ & $\begin{array}{c}\text { June } \\
\text { Frame } \\
\text { Percent }\end{array}$ & $\begin{array}{c}\text { November } \\
\text { Sample }\end{array}$ & $\begin{array}{c}\text { November } \\
\text { Frame Percent }\end{array}$ & $\begin{array}{c}\text { Total } \\
\text { Sample }\end{array}$ \\
\hline \multirow[t]{3}{*}{ High-Tech } & & 2,593 & & 1,276 & & 3,869 \\
\hline & Yes & 361 & 100.0 & 166 & 100.0 & 527 \\
\hline & No & 2,232 & 100.0 & 1,110 & 100.0 & 3,342 \\
\hline \multirow[t]{3}{*}{ Medium-Tech } & & 5,769 & & 1,805 & & 7,574 \\
\hline & Yes & 1,029 & 23.8 & 237 & 19.5 & 1,266 \\
\hline & No & 4,740 & 26.0 & 1,568 & 26.6 & 6,308 \\
\hline \multirow[t]{3}{*}{ Non-Tech } & & 15,580 & & 5,446 & & 21,026 \\
\hline & Yes & 2,090 & 6.5 & 670 & 6.7 & 2,760 \\
\hline & No & 13,490 & 10.3 & 4,776 & 10.7 & 18,266 \\
\hline Total & & 23,942 & 12.7 & 8,527 & 13.5 & 32,469 \\
\hline
\end{tabular}

\section{DATA COLLECTION PREPARATION}

\section{Respondent Materials Development}

Designing respondent materials that appeal to a diverse sample such as that in the KFS is a major challenge. The language must be clear and concise enough to convey the impression that the survey is important. Also, care must be taken in the use of language to ensure the documents can be read and understood by persons of different levels of literacy.

Several documents produced by MPR project staff were used in the Baseline Survey. After the materials were drafted, they were reviewed by an independent MPR staff member in accordance with MPR's quality assurance (QA) policies. Comments from the QA reviewer were incorporated, and the materials were then sent to MPR's editing department for review. Project 
staff finalized the edited versions before the survey director approved the final versions for use in the field.

The documents produced included the following:

- Advance Letter. The advance letter was the first contact with KFS Baseline sample members. It introduced the study, asked for cooperation, and provided web login information and contact information for MPR staff members.

- Web Instructions. The web instructions document included step-by-step instructions on how to access the KFS web survey. It also included the web login information and a screenshot of the survey login screen as a visual aid.

- Frequently Asked Questions (FAQs). This one-page document provided answers to some common questions sample members were likely to have about the survey, MPR, and the Foundation.

- Reminder Postcard. This was sent as a reminder to respondents who had not completed the web survey. The postcard provided the survey web address and encouraged respondents to log on to the website and complete the survey.

- Refusal Letter. This letter was sent to the respondents who refused to do the survey after they were contacted by telephone. It was the first effort at refusal conversion.

- Email Message. An email message was sent to sample members who requested additional information about the study to be sent to them via email. Sample members made these requests either when contacted by telephone or by independently contacting MPR through email. It included the web login information and also a concise version of the FAQs.

- Fax. This was a letter sent to a small percentage (less than 1 percent) of the sample that requested additional information via fax. The document was on MPR letterhead and was very similar in form and content to the email request.

Copies of the respondent materials are included in Appendix G.

\section{Interviewer Training Materials}

Project staff produced a set of training materials for the KFS Baseline interviewer training, including a training manual that was provided to telephone interviewers and supervisors prior to the session. The first chapter of the manual provided information on the background of the study, explained the eligibility criteria for both respondents and businesses, and stressed the importance of confidentiality. The second chapter covered general interviewing skills; reviewed 
the procedures for contacting sample members; and reviewed how to handle certain situations, such as scheduling appointments, requests for new letters, dealing with privacy managers and cell phones, and handling requests for more information. The third chapter covered effective engagement and rapport building with respondents, refusal avoidance and conversion, and strategies for handling gatekeepers. The fourth and final chapter was a question-by-question

review of the entire survey instrument. Survey questions were displayed via screen shots and additional information about questions was provided below the screen shot. Additional exhibits, such as a copy of the advance letter, reminder postcard, and FAQs, were also included in the manual.

The KFS project team also developed an FAQ sheet specifically for interviewers. This version of the FAQ stressed the importance of the study; provided information about the Foundation and MPR; and contained responses to common objections to participation, such as lack of available time, lack of interest, and confidentiality concerns. The responses to questions and objections were written to be more conversational than those in the FAQ sheet included in the advance mailing.

\section{Survey Operations Center (SOC) Staff Training}

All new MPR interviewers complete a 12-hour general interviewer training (GIT) program, which explains the role of the telephone interviewer and emphasizes effective techniques for conducting and establishing rapport with respondents. Other topics covered during the GIT include instruction on reading all questions exactly as worded and in a neutral and unbiased way, probing techniques, and the need for a professional and confident tone of voice. This training is conducted through the use of videotapes, the web, written materials, practice interviews, role playing, and one-on-one instruction. 
KFS project-specific interviewer training was conducted over an additional 12 hours, in three 4-hour segments for evening interviewers and two 6-hour segments for daytime interviewers. Because the KFS sample was nationwide and many businesses were home based, evening calling was necessary to contact a substantial portion of the sample.

The KFS interviewer trainings were designed to give the interviewers and supervisors maximum exposure to the topics that would allow them to engage effectively and recruit sample members for the Baseline Survey. Emphasis was placed on:

- Background on project goals

- Importance of interviewer roles

- Confidentiality

- Importance of initial contact

- Overcoming objections

- Introducing the study effectively

- Dealing with gatekeepers

- Refusal avoidance and conversion

- Frequently asked questions

- Getting accurate contact information to be used in future followups

These topics were reviewed in the first eight hours of training. The last four hours consisted of "hands-on" training. The hands-on training paired interviewers, with one playing the role of respondent and the other playing the interviewer role. Detailed mock interviews were developed by the project staff for the "respondents," in order to assure that each pair of interviewers had the same experiences. In addition, engagement scenarios were part of the paired practice. These scenarios again required interviewer pairs to alternate between the respondent and the 
interviewer roles, but this time the focus was on overcoming objections and answering the most common questions respondents were likely to ask.

As discussed in greater detail later, monitoring of all interviewers was conducted to assure data quality and proper execution of the research protocol. Monitors focused on interviewers who had difficulty gaining cooperation of respondents and provided suggestions for improvement. The SOC staff and project staff would regularly review cooperation rates and productivity rates and identified interviewers in need of additional coaching. As the study continued, interviewer attrition as well as the release of more samples required additional interviewer training sessions.

\section{Advance Mailings}

The first contact made with KFS Baseline sample members was the advance letter package. It consisted of an advance letter, a web instruction sheet, and an FAQ sheet.

The advance letter, printed on MPR's letterhead, contained a brief introduction of the study and highlighted the importance of participating in the survey. It also gave information on the research sponsor and introduced MPR as the independent firm conducting the research. The letter contained the business-specific web login ID and password used to log on to the study website to complete the survey. The last piece of information provided in the letter was the project's 800 number, website, email address, and contact person. This information was provided to give sample members the option of contacting MPR if they had further questions or if they preferred to call in to complete the survey or make an appointment to do so.

The second piece within the packet was the web instruction sheet. This provided step-bystep instructions on how to complete the web survey and included the study's website address, the business-specific login ID and password, and instructions on how to access the survey online. 
It also reassured the respondent that the site is secure and that no one outside of MPR would have access to his or her information.

The third piece within the mailing was the FAQ sheet to provide additional information and answer some common questions about the study. This was a generic sheet that was sent to all Baseline sample members.

Advance packages were sent to 32,469 businesses during the Baseline Survey in six batches or sample releases. The packages were mailed in MPR's standard business envelopes. Before each mailing was delivered to the post office, MPR inspected 5 percent to 10 percent of the packets for consistency and accuracy.

\section{Postcard Mailings}

A reminder postcard was sent to each sampled business that did not complete the study on the web one week after the advance mailing. The postcard included the name of the owner, if known, and the name and address of the business. Information about the study and the website address and MPR contact information were provided on the postcard, and respondents were encouraged to make contact with MPR if they had lost or forgotten their password and login ID. The postcard labels were generated through MPR's Sample Management System (SMS). Postcards were also inspected for consistency with U.S. postal mailing standards prior to mailing.

\section{Response Protocols to Sample Member Inquiries}

Handling inquiries from respondents promptly and effectively helps establish good rapport with the sample members and thus increases the chances of their completing the survey. During the Baseline Survey, respondents were supplied with several ways to contact MPR:

- Project toll-free telephone number 
- KFS email

- Project staff telephone numbers

- Fax requests

The toll-free telephone number provided to sample members was monitored by MPR's trained staff at the SOC during business hours. A respondent could call the toll-free number to complete the survey on the telephone or make an appointment to have an interviewer call back and administer the survey. Respondents could also call to inquire about the survey and to verify its legitimacy.

Another important function of the toll-free number was to provide login and password information to sample members who wanted to complete the web survey but had misplaced their login and password information. Help desk staff members were trained to identify callers through a lookup file and to make sure that they provided the information to a legitimate owner of the sampled business. If help desk staff were unable to answer all of a sample member's questions, the survey director's phone number was provided.

Some sample members and gatekeepers requested that an email message be sent with information explaining the survey and how to participate. The email that was sent to requests such as these included an abbreviated version of the FAQs, along with the password, login ID, and website information. More than 700 of these emails were sent over the course of the KFS Baseline Survey. The email address obtained in responding to these requests was preserved so that it could be used to contact eligible sample members during the First Follow-Up.

When contacted by telephone, approximately 150 sample members asked that a fax be sent to them instead of a letter or email. Staff designed a letter that contained the web login information as well as the FAQs to respond to these requests and faxed it to the respondents, usually on the same day of the request. 


\section{Respondent Incentives}

Research has shown that response rates for surveys offering incentives are generally higher than for surveys not offering any incentives. As discussed in Section B, MPR conducted an incentive experiment during Pilot Test 2. Although results of this experiment showed no statistical difference in completions among the postpayment groups, there was evidence of a directional effect (232 completed from the incentive treatment versus 168 in the control group), which argued for including an incentive in the Baseline Survey design. Although higher incentives generally produce higher levels of participation, there is also a risk in offering substantial financial incentives, since respondents may feel compelled to participate and the research will no longer be truly voluntary.

During the KFS Baseline Survey, we offered eligible sample members $\$ 50$ for completing the survey. Respondents received the same incentive if they completed the survey on the web or via the telephone. The incentive was not offered as a payment for the sample members' time, but it was referred to in the advance materials and during telephone contacts as a "token of appreciation" for their participation. We made this distinction because if the $\$ 50$ were presented as compensation for their time, some owners would think the payment insufficient and refuse to participate. Instead, the incentive was presented more as an honorarium or a way of thanking the owner for participating in the study.

KFS incentive checks were mailed weekly in order to ensure that respondents received them promptly. If a respondent payment was returned to MPR from the post office without forwarding information, it was sent to locating in order to obtain an updated postal address. The check was then reissued and sent to the new business location. If a check was returned with forwarding information, then the correction was noted in the SMS, and the check was reissued and sent to the forwarding address. 


\section{E. DATA COLLECTION}

\section{Timing of Sample Releases}

Data collection for the KFS Baseline Survey began on July 28, 2005, and concluded on July 29, 2006. The sample was fielded in six separate releases, and each release began with an advance letter mailing to sample members. The dates of all six sample releases (defined as the date of the advance mailing) and sample sizes of each release are listed in Table 7.

Adjustments were made to the initial mailing for some cases. First, because of Hurricane Katrina, some New Orleans and other Gulf Coast zip codes were not accepting mail in the aftermath of the storm. Sample members in Release 2 in these zip codes did not receive the mailings and were not called for three months after the storm. We resumed calling these cases in December 2005.

TABLE 7

KFS BASELINE SURVEY RELEASES

\begin{tabular}{lcc}
\hline Sample Release & Release Date & Sample Size \\
\hline 1 & $7 / 28 / 2005$ & 4,001 \\
2 & $9 / 23 / 2005$ & 5,999 \\
3 & $11 / 04 / 2005$ & 1,192 \\
4 & $11 / 25 / 2005$ & 7,400 \\
5 & $1 / 11 / 2006$ & 6,626 \\
6 & $2 / 28 / 2006$ & 7,251 \\
\hline Total & & $\mathbf{3 2 , 4 6 9}$ \\
\hline
\end{tabular}

Second, cases that did not have an owner name were mailed with the letter addressed to the title provided by D\&B, often "Owner" or "Principal." Interviewers reported that it was much more difficult to make initial contact with cases without an owner name. Asking for the owner of a business without having a name made the call sound like a sales solicitation. Therefore, after the first release, these cases were sent to locating prior to sending the advance mailing to 
see if an owner name could be obtained. Cases for which an owner name was found were updated, and the advance letter and postcard were then mailed one week apart. If no owner name could be found, a letter addressed with the title of the "Owner" or "Principal" was sent.

Some of the addresses to which the advance mailing was sent were not accurate, resulting in returned mail. When the returned mail included an updated address, this was recorded in the SMS and the mailing was resent. When there was no such address, the existing address was recorded as inaccurate to prevent any re-mails to that address, and the case was sent to locating to search for a new address.

When sample members, after receiving the advance mailing, completed the survey or attempted to complete it but were screened out, their cases were removed from the CATI system so they would not be called. Response to the initial mailing was low for all six sample releases. During the first two weeks between the advance mailing and the start of telephone followup, between 2 percent and 3 percent of the businesses accessed the web survey, answered the screening questions to determine if the business was eligible, and completed the survey. This low level of response necessitated a significant level of effort to complete the remaining interviews by CATI.

\section{Schedule of Contacts to Sample Members}

The general schedule of contacts to sample members was an advance letter, followed one week later by a reminder postcard, followed one week after that with the beginning of telephone interviewing. The reminder postcard was tested for effectiveness in the first release. Of the 4,001 cases in the initial release, 2,037 were randomly selected to receive a reminder postcard one week after the letter was sent, while the remaining cases were not. Cases that had completed the interview by the time of the postcard mailing were not sent a postcard. One week after the postcard was sent, telephone interviewing began. 
Because the results indicated a slightly higher completion rate for cases that received the postcard than for those that did not (15.2 percent versus 14.5 percent as of October 31,2005$)$, and because of the low cost of a postcard contact, all subsequent releases received both the advance letter and a postcard.

The main purpose of this contact schedule was an attempt to give sample members enough time to $\log$ on to the web and complete the survey themselves, in order to reduce telephone interviewing costs. The mailing also provided information to sample members that might help telephone interviewers persuade them to complete the study.

When CATI interviewing began, calls were delivered to telephone interviewers via the CATI call scheduler. This scheduler assures that scheduled callbacks are met and that cases that do not result in contact, such as answering machines and no answers, are tried at different times of the day and evening and on weekends. A standard answering machine message was also left at periodic intervals. This interval was designed to avoid irritating the sample member, and it also gave the sample member time to respond to the message before the next call. Cases with wrong numbers and those with a series of no contacts were sent to locating.

As discussed earlier, sample members or gatekeepers occasionally requested additional information, emails, or faxes to explain the study. These emails and faxes were sent, and the case was not called for 10 days to allow the sample member time to respond. Additional contacts for cases that refused are discussed in a later section, as are a variety of contact procedures for special types of cases. In addition to setting scheduler parameters, sending emails on request, and other procedures, a variety of additional steps helped increase the efficiency of the CATI effort. 


\section{Survey Management Techniques}

Survey management involves issues of scheduling, monitoring progress, and evaluating procedures to make CATI interviewing as efficient as possible. One of the most important aspects of efficient interviewing is proper matching of available sample and interviewer hours. Project staff coordinated training schedules and sample releases with interviewer schedules. This coordination was designed to ensure that interviewer hours were highest when new sample was released, so that the initial contact with the sample members took place two weeks after the advance letter was mailed. As additional sample was released, interviewer hours increased again and then decreased gradually as the sample was thoroughly worked.

Project staff conducted weekly reviews of interviewer productivity, cooperation rates, calls per hour, and monitoring reports. As discussed earlier, interviewers who were having trouble completing cases were provided retraining and additional monitoring to help them improve. Individual one-on-one sessions were also conducted with interviewers with lower-than-average cooperation rates. Supervisors wrote up summaries of these sessions and passed them on to other project staff. Emphasis was placed on the importance of completing the screener, in order to determine if a case was eligible to complete the study. The KFS staff reviewed the best times of the day or evening to reach respondents and compared that information with interviewer schedules to ensure adequate coverage throughout the entire calling day.

As in most large CATI projects, getting the final 10 percent of completes takes significantly more resources than any other group of completes. As the KFS Baseline Survey was coming to an end, the sample had been thoroughly worked. Sample members had been contacted, and interviewers had made their best attempts to complete the study with them. KFS project staff implemented several steps to complete the remaining interviews. Among these steps were: 
- Sending an additional letter to "no-contact" and pending cases. This letter emphasized that the project needed their participation, reminded them of the incentive, and asked them to complete the study.

- Focusing locating efforts on cases that had not been worked completely, while finalizing those that had been worked thoroughly as "unlocatable."

- Targeting a letter to the remaining partially completed cases. These cases were particularly valuable to the project, since they had completed the screener section of the interview and were determined to be eligible. Because of the high importance of this group, a $\$ 5$ cash incentive was included with the letter. Project staff regularly printed out lists of these cases and gave them to interviewers to ensure that they were contacted frequently.

- Adjusting interviewer schedules to ensure that Pacific time zone cases received sufficient call coverage.

- Developing a special answering machine message to replace the initial message, indicating that the study was ending and this was the last opportunity to participate.

Even with all these efforts, productivity rates fell and costs per complete rose dramatically in the final months of data collection. Project staff, the Foundation, and the principal investigator discussed the trade-offs between reaching the original goal of 5,000 completes versus the project's budget constraints. Out of that discussion came the decision to complete at least 4,900 interviews and end data collection on July 29, 2006, making the field period exactly one year.

\section{Refusal Conversion}

The primary reason to try to convert refusals is to ensure that the sample is representative of all sample members. Without refusal conversion, there is a chance that results would be skewed toward people who like to do surveys or who are interested in the particular topic. These sample members may answer the questions differently from people who initially refuse to participate in a research study. In order to get as representative a sample as possible, refusal conversion techniques were used on the KFS Baseline Survey to persuade and convert sample members who initially refused. 
As detailed in Section D.3 on training, significant emphasis was put on refusal avoidance. Interviewers practiced how to respond to objections, particularly when sample members cited a "lack of time" or indicated they were "not interested." Despite this training and practice, the survey yielded a high rate of refusals, with 2.5 refusals on average for each completed CATI interview. New business owners are very focused on getting their businesses off the ground, and many were not interested in participation in a survey. Many gatekeepers were suspicious of the study, suspecting that the survey was a disguised sales pitch.

With the high rate of refusals, many cases were available for a refusal conversion effort. A few techniques were used in the attempt to convert these cases. First, all refusal cases were put on hold for 14 days. During this time, a refusal letter was sent to the business. It acknowledged the refusal but emphasized the unique nature of the study and the importance of participation. Once again, the website of the survey was provided, along with the sample member's password and login ID. After the 14-day waiting period, if the sample member had not completed the survey on the web, interviewers trained in refusal conversion techniques called the case. Refusal conversion training was conducted for KFS interviewers who had demonstrated the ability to build rapport and had higher-than-average cooperation rates.

Training on refusal conversion emphasized being quick to respond to objections, being confident and knowledgeable in the presentation of material, and calling with the expectation of success. Converters were trained to emphasize the $\$ 50$ incentive, but to make sure to present it as a token of appreciation. Other topics covered in the refusal conversion training included the most common objections for refusals and how to address them, and making sure that interviewers did not take the refusals personally. Finally, refusal conversion training stressed including accurate notes on the cases to help refusal converters making future attempts understand the objections or concerns expressed by the sample member. 
All cases that refused a second time were finalized. Project staff reviewed the few very adamant first refusals to see if they should be finalized without a conversion attempt. Project staff struck a balance between avoiding calling people who were adamantly opposed to another call and giving business owners a chance to change their minds about participation.

Of the 9,739 cases that initially refused, 525 were converted and completed, while an additional 1,143 initial refusals were recontacted, screened, and found to be ineligible. This means that approximately 17 percent of initial refusals were resolved as something other than a final refusal, and that initial refusals constituted about 11 percent of all completes.

While refusal cases were the most challenging on the KFS Baseline Survey, a number of other types of cases required special handling and review.

\section{Handling Special Cases}

During the KFS Baseline Survey, four groups needed special handling: (1) businesses in the sampling stratum of high-tech industries, (2) those with no suitable owner to respond to the survey, (3) cases with language barriers, and (4) those with partially completed web surveys. These groups of cases were routed to interviewers who received special training on how to resolve them.

\section{a. Businesses in the High-Tech Sampling Stratum}

As discussed in Section C, there were two high-technology sampling strata of cases (hightech and medium-tech). The businesses in the high-tech sampling stratum received special handling. Because refusal rates tend to be higher among new interviewers, these high-tech cases were initially limited to interviewers who had worked on the KFS Pilot Test 2. This prevented a large number of initial refusals resulting from interviewer inexperience. 


\section{b. No Suitable Owner Cases}

There were situations in which the owner of the business or a gatekeeper indicated that there was no qualified owner-operator-founder of the business. This would often occur when the interviewer asked to speak to the owner of the business that $\mathrm{D} \& \mathrm{~B}$ provided, only to find out from a gatekeeper that this owner was not there and no other owner was available. Because the unit of analysis for the KFS is the business and not the individual owner, cases could not be screened out based upon the listed individual's not being an owner-operator-founder. Project staff selected interviewers with excellent engagement techniques and a thorough understanding of these cases and trained them to find the answers to the following questions:

- Is there another owner-operator-founder of the business available? If so, the screening and interview would proceed.

- Is the case really a refusal? Some people may answer "no" to the questions about eligibility because they do not want to do the study and are really refusing. If this were the situation, the interviewer would code the case as a refusal and standard refusal conversion techniques followed.

- Is there actually no one at the business who qualifies as an owner-operator-founder? An example of this occurred when the only founder of the business sold out to someone who currently operates the business but was not involved in its founding. This would be a case that would be finalized because no suitable owner could be found.

Project staff provided a suggested introduction for these cases but also allowed interviewers to use their discretion as to how best to approach them.

\section{c. Language Barrier Cases}

There were 431 cases in which no owner who spoke English could be located. These cases were divided into those in which Spanish was spoken (276), and those in which some other language was spoken (155). Because there were not a significant number of cases in any one language (Spanish cases made up less than 1 percent of the total sample), it was decided not to 
have the instrument translated. Translating a survey can be costly, since it requires significant translation, programming, and testing time. As such, the benefits of having a translated version of the survey did not justify the costs given the very small number of language barrier cases. For the cases in which Spanish was spoken, bilingual interviewers called and followed these procedures:

1. Verify that it was the correct business.

2. Verify that it was a Spanish-language case, and there was no eligible respondent who spoke English.

3. If there was no eligible respondent who spoke English, proceed through the screener portion of the instrument to see whether or not the case was eligible.

4. If the business was screened as eligible for the study, verify that the owner would be unable to do the study in English. After the engagement process and the five-minute screener, the owner might feel more comfortable about the study and might be willing to try to do it in English.

5. If the business was eligible for the study but there was no owner to complete the study in English, the case was coded out as a final status language barrier.

When Spanish was not the language spoken, specific interviewers were trained to:

1. Verify that it was the correct business.

2. Verify that a language barrier existed, and there was no English-speaking owner.

3. Determine, when possible, which language was spoken. These cases would also be coded out as final status language barrier.

\section{d. Web Partial Cases}

Web partials were cases in which the sample member logged on to the web survey, completed one or more questions, and then logged off before completing. Sample members partially completing the survey were contacted by highly experienced interviewers who followed these procedures:

1. Examine the case before calling, so that the interviewer knew at what point in the interview the sample member broke off. This would enable the interviewer to tell the sample member how much longer it would take to complete and would also help 
the interviewer get to the last unanswered question quickly if the sample member agreed to complete the interview.

2. Call the respondent, acknowledging that he or she did partially complete the study. Interviewers were trained to emphasize the \$50 incentive for completion and offer to complete it with the sample member over the phone. Also, interviewers were instructed to tell the sample member roughly how much time it would take to complete the interview and assure the sample member about the confidentiality of the survey data.

3. Emphasize to anyone other than the sample member answering the phone that the sample member has already done some of the study, so it has obvious interest to him or her.

4. Include concise and complete notes for cases in which the sample member was contacted but did not complete the study.

Besides these four groups, a smaller number of cases required specialized handling. There were rare occasions when the web server went off-line for maintenance, and the project mailbox received email messages from sample members who had tried to log on to the survey but had been unable to do so. Project staff responded quickly to these messages, apologized to the sample members affected, and let them know when the problem had been resolved and that they could log on to complete the interview.

\section{Use of Updated D\&B Files}

As discussed in Section C, D\&B provided an updated file to MPR in November 2005. This file contained new records of businesses with start dates in 2004, as well as updated information on businesses that had been in the original sampling frame. This updated information included new owner names and titles, new business addresses, and new phone numbers for cases already released for data collection. These updated data were examined carefully and compared with the

existing data. Some cases with updated information had already been completed, and information provided by the sample member was considered the best information and not corrected with the updated D\&B information. When no additional information had been 
gathered by MPR in the interviewing and locating process, the updated data were integrated into the KFS database to provide interviewers with the most current contact information.

The updated data also reported some KFS cases already released for data collection as out of business. These were typically cases that were in locating. Because D\&B reported them as out of business, project staff finalized them with no additional locating or interviewing attempts. The updated information on addresses and phone numbers also helped the locating process, which is outlined below in Section E.8.

\section{Monitoring and Data Quality}

Monitoring interviewer performance helps improve data quality and also provides an opportunity to improve interviewer techniques on sample member engagement and refusal avoidance. The monitoring process also helps identify issues with survey questions that may not have been anticipated and provides support for interviewers who may have questions about individual survey items.

MPR emphasizes the importance of the monitoring process, and the MPR monitoring software allows staff conducting the monitoring (monitors) to enter evaluations of interviewer performance into the system easily, where it is stored for retrieval by supervisors and project staff. All KFS monitors attended the interviewer training in order to understand project requirements fully. At the beginning of the data collection, project staff also monitored interviewers to evaluate the performance of the survey instrument and to provide feedback on interviewer performance.

Monitoring consisted of listening carefully as the interviewer engaged the sample member or gatekeeper, while also observing the interviewer's screen to check for accurate coding and correct computer logic. After the monitors observed the interviewer and wrote up their 
evaluations, they would meet with the interviewer to review the case or the engagement, point out interviewer strengths, and make suggestions for improvements.

Monitoring reports were generated weekly and included data such as the number and type of mistakes each interviewer was making and the number of positive comments made by the monitor. Interviewers with multiple mistakes were monitored more intensely and also retrained as necessary. Again, particular emphasis was placed on quick reaction time to respondent comments and effective engagement techniques.

In the first few days of calling, monitoring and interviewer comments revealed a few issues, such as that some businesses did not have an owner at the number provided by D\&B and that the sample contained a few duplicate cases. Areas in which interviewers were having some difficulty, such as coding cases as out of business and updating owner and business names, were also identified.

Another issue that was discovered during monitoring was the tendency by some respondents to count debt amounts in multiple categories of the questionnaire. In order to address this double counting, wording was added at the beginning of each debt section to indicate that each section should not include debt that would be better recorded in another category, and that all debt should be counted only once.

To review training issues and to provide a forum for interviewer comments on the project, interviewer debriefings were carried out within one month of the start of the telephone interviewing. Interviewers asked questions of project staff, indicated the areas in which they needed help, and shared successful techniques with project staff and other interviewers. The interviewers could also express their frustrations with the difficulty of the project. Because of the low eligibility rate, interviewers often worked hard to gain a respondent's cooperation only to have the respondent become ineligible instead of a completed case. 
Specific issues discussed and feedback the project team received at the debriefing included:

- Interviewers reported the difficulty of coding out-of-business cases and making changes to names of owners and businesses. As a result of these comments, all interviewers underwent brief refresher training on these issues. The refresher training also included a review of initial engagement and refusal avoidance procedures.

- Interviewers were initially provided with several documents containing reference materials about the project and indicated that it would be helpful to have a one-page summary containing the project's 800 number, the web addresses for the survey as well as for the Foundation and MPR, and the answers to the most common FAQs. This was developed by project staff and distributed to interviewers.

- Respondents would sometimes report that the business had not started, but the screener considered it to be an operating business. Project staff and the interviewers discussed that deciding when a business "starts" is subjective and that some businesses would be eligible for the study despite not having made any sales. Also reviewed was the issue of the purchase of an existing business and why that could qualify as a "new" business, and the purchaser of the business as a "founder."

- Interviewers reported that many respondents did not know anything about $\mathrm{D} \& \mathrm{~B}$, the source of the sampling frame. The FAQ sheet was revised to add additional information about D\&B.

- As previously discussed, interviewers reported problems with cases for which there was no name for the principal. Therefore, cases in subsequent sample releases that were missing owner names were sent to locating prior to being released to interviewing.

- The introduction to the survey seemed wordy to many interviewers, and the interviewers were encouraged to try different introductions. The project staff emphasized that the introduction used must include the name of the interviewer, the sponsoring organization, and what the study is about. Interviewers, however, could develop an introduction that they were comfortable with and that they could deliver smoothly and naturally.

- Interviewers mentioned that the following techniques had helped them build rapport and persuade sample members to participate: providing sample members with the Kauffman Foundation website to increase credibility, learning to balance the amount of information to give to gatekeepers, varying introductions, and providing some brief information about the Foundation.

Additional interviewer debriefings were held throughout the field period. While some of these reviewed particular points about the instrument, the debriefings were mainly sessions to 
continue to encourage the interviewers and to ask them to share ideas to increase cooperation rates.

As another step to ensure data quality, a thorough review of data took place at two benchmarks in the study-after the first 100 interviews were completed and again at 500 completes. Project staff conducted a review of the data to examine skip patterns, "OtherSpecify" fields, and other data for accuracy. These reviews uncovered no significant problems with the web and CATI instruments.

\section{Locating}

As mentioned earlier, cases requiring locating may be systematically different from those that do not. To ignore businesses that have moved or changed contact information runs the risk of excluding businesses that differ from those that are easier to contact. For the KFS, a substantial locating effort was made to find each listed business that we could not contact using the initial D\&B data. While the $\mathrm{D} \& \mathrm{~B}$ database provides names, addresses, and phone numbers of the businesses, the fact that these are new businesses means that some of them will never become established. Others will move or change phone numbers, in part because they are homebased businesses and the business owner might move.

Locating also provided another important function for cases that did not have an owner name. After Release 1, these cases were sent to locating in an attempt to find the name of the owner to help facilitate the initial telephone contact.

The KFS locating process used the following resources to locate sampled businesses or principals: zip key, directory assistance, Lexis-Nexis, ACCURINT, and other Internet searches. All of these resources provided names, addresses, and/or phone numbers of individuals and businesses or helped verify existing contact information. Through systematic use of these resources, locators could sometimes determine if a business was still operating and could 
discover updated contact information. If cases were confirmed as still in business, they were returned to interviewing for additional attempts. A supervisor would examine a case without any new leads to determine what further action, if any, should be taken.

The SMS was the clearinghouse for information about locating attempts, as well as all mail contacts attempted with sample members. Each letter and postcard that was sent to sample members was recorded, as were new addresses, phone numbers, and owner names. Information gathered by telephone interviewers was also passed to the SMS. The SMS also has management tools for performance evaluation, allowing locating supervisors to measure the effectiveness of individual locators. Finally, the SMS allows supervisors to look at cases that have been thoroughly worked and, when no further locating action is warranted, to finalize them as "unlocatable."

Because of the low eligibility rate, knowing when to make a case unlocatable was crucial to the success of the KFS. During the KFS Baseline Survey, more than 12,400 cases required some degree of locating services. Of these, about 2,500 were finalized as unlocatable, meaning that approximately 80 percent of all cases sent to locating were located.

\section{Response Rates}

Response rates are measures of the "potential" for nonresponse bias and of the quality of a survey. To calculate the response rate for the KFS Baseline Survey, we used a standard algorithm recommended by the American Association for Public Opinion Research (AAPOR). In this computation, the unweighted response rate is the count of the number of completed interviews among eligible businesses divided by the estimated total count of eligible businesses (the weighted response rate is comparable to the substitute of weighted estimates for the counts). We will provide these response rates using two definitions for eligibility: 
1. Eligible businesses include only businesses that met the criteria on starting in 2004 operating at the time of data collection

2. Eligible businesses include businesses that met the criteria on starting in 2004, plus businesses that were not operating at the time of data collection

The two definitions differ on the inclusion of eligible businesses that are not in operation at the time of the survey.

Using AAPOR response rate 3 algorithm, we assumed that all businesses with unknown eligibility (using either eligibility definition) would be eligible at the same rate as businesses we were able to contact and screen. The AAPOR response rate is computed under the first eligibility definition:

$$
R R=\frac{\text { Completes }}{\text { Completes }+ \text { Elig. Non-completes }+ \text { Unknown Elig. } \times \text { Est. Elig. rate }}
$$

where the estimated eligibility rate is defined as:

$$
\text { Est. Elig. rate }=\frac{\text { Completes }+ \text { Elig. Non-completes }}{\text { Completes }+ \text { Elig. Non-completes }+ \text { Ineligibles }}
$$

Under the second eligibility definition, the AAPOR response rate is computed:

$$
R R=\frac{\text { Completes }+ \text { Non-operational Businesses }}{\text { Completes }+ \text { Non-operational Bu } \sin \text { esses }+ \text { Elig. Non-completes }+ \text { Unknown Elig. } \times \text { Est. Elig. rate }}
$$

where the estimated eligibility rate is defined as:

$$
\text { Est. Elig. rate }=\frac{\text { Completes }+ \text { Non }- \text { operational Businesses }+ \text { Elig. Non-completes }}{\text { Completes }+ \text { Non }- \text { operational Businesses }+ \text { Elig. Non-completes }+ \text { Ineligibles }}
$$


Among the 32,469 cases we released to the field, we completed interviews with 4,928 eligible businesses. We also identified a sizeable number of businesses that had ceased operations. For example, 7 percent were out of business within the half-year interval between the two D\&B files we received, and during the one-year data collection period, 17 percent of the selected cases were out of business. A large number of businesses $(5,604)$ were identified as ineligible for the study. As discussed earlier, this high ineligibility rate was due to the rigorous screening we implemented to create a consistent panel of businesses starting operations in 2004. A total of 1,102 businesses finished the screening process and were eligible for the study but did not complete the interview. The remaining businesses had unknown eligibility for the survey because we were unable to screen them for eligibility. The overall unweighted AAPOR response rate is then calculated as 43.4 percent under the first eligibility definition, and as 48.1 percent under the second eligibility definition.

In general, unweighted response rates measure the proportion of the sample that resulted in useable information for analysis. Weighted response rates can be used to estimate the proportion of the survey population for which useable information is available and is generally considered as a measure of the potential for nonresponse bias. Because we oversampled the businesses in the high-tech sampling stratum, the weighted response rate may result in different values. With the sampling weights incorporated, the weighted AAPOR response rate is 42.5 percent under the first eligibility definition and 47.6 percent under the second eligibility definition. ${ }^{7}$ Table $8 \mathrm{~A}$ and 8B show the unweighted/weighted response rates across the three technology sampling strata under the two eligibility definitions.

\footnotetext{
${ }^{7}$ The calculation for the sampling rate is discussed in Section G.2.
} 
TABLE 8A

WEIGHTED AND UNWEIGHTED AAPOR RESPONSE RATES

ACROSS TECHNOLOGY SAMPLING STRATA UNDER

FIRST ELIGIBILITY DEFINITION

\begin{tabular}{ccccccc}
\hline $\begin{array}{c}\text { Technology } \\
\text { Sampling } \\
\text { Strata }\end{array}$ & Completes & Ineligibles & $\begin{array}{c}\text { Eligible Non- } \\
\text { Interviews }\end{array}$ & $\begin{array}{c}\text { Unknown } \\
\text { Eligibility }\end{array}$ & $\begin{array}{c}\text { Unweighted } \\
\text { AAPOR RR } \\
\text { (Percent) }\end{array}$ & $\begin{array}{c}\text { Weighted } \\
\text { AAPOR RR } \\
\text { (Percent) }\end{array}$ \\
\hline High-Tech & 705 & 1,346 & 169 & 1,649 & 46.3 & 46.3 \\
$\begin{array}{c}\text { Medium- } \\
\text { Tech }\end{array}$ & 1,329 & 2,681 & 195 & 3,369 & 48.4 & 48.6 \\
Non-Tech & 2,894 & 7,201 & 738 & 10,193 & 41.1 & 41.6 \\
\hline Total & $\mathbf{4 , 9 2 8}$ & $\mathbf{1 1 , 2 2 8}$ & $\mathbf{1 , 1 0 2}$ & $\mathbf{1 5 , 2 1 1}$ & $\mathbf{4 3 . 4}$ & $\mathbf{4 2 . 5}$ \\
\hline
\end{tabular}

TABLE $8 B$

WEIGHTED AND UNWEIGHTED AAPOR RESPONSE RATES

ACROSS TECHNOLOGY SAMPLING STRATA UNDER SECOND ELIGIBILITY DEFINITION

\begin{tabular}{cccccccc}
\hline $\begin{array}{c}\text { Technology } \\
\text { Sampling } \\
\text { Strata }\end{array}$ & Completes & $\begin{array}{c}\text { Out of } \\
\text { Business }\end{array}$ & Ineligibles & $\begin{array}{c}\text { Eligible } \\
\text { Non- } \\
\text { Interviews }\end{array}$ & $\begin{array}{c}\text { Unknown } \\
\text { Eligibility }\end{array}$ & $\begin{array}{c}\text { Unweighted } \\
\text { AAPOR } \\
\text { RR }\end{array}$ & $\begin{array}{c}\text { Weighted } \\
\text { AAPOR } \\
\text { RR }\end{array}$ \\
(Percent)
\end{tabular}

\section{Cohort Maintenance Packet}

The strength of the data collected during the KFS is their longitudinal nature. In order to minimize attrition in the panel between surveys, we made significant efforts to express appreciation to panel members. The $\$ 50$ incentive was one method of both thanking the 
respondent for participation in the Baseline Survey and encouraging participation in future follow-up surveys. Another technique to remind panel members about the KFS was the packet of materials sent after they completed the Baseline Survey that welcomed them as participants in the study. In addition to welcoming panel members, the packets provided another opportunity to gather updated contact information.

The KFS welcome packet consisted of a welcome letter, a brochure on the Kauffman Foundation, and a pen with the inscription "Kauffman Firm Survey." The welcome letter thanked respondents for completing the survey and reminded them that this is a multiyear study and that we would be contacting them again for a follow-up interview in the upcoming year. The letter also contained contact information for MPR's survey director as an additional means to contact the researchers. The brochure provided information about the Foundation and its mission. It was decided to provide only basic descriptive information about the Foundation rather than offering information that might encourage panel members to seek out business development resources available from the Foundation that could create bias among panel members and compromise the study.

The third item included in the packet was the "Kauffman Firm Survey" inscribed pen. This item was included to provide something that would be useful as well as a visible token as sample members conduct their business activities. It would also serve as a reminder of the study that would make conducting the follow-up survey easier.

The welcome packet was designed as an attractive piece of mail to avoid it being identified as another piece of junk mail and thus discarded or ignored. To this end, a large $51 / 2 "$ x 8 " envelope was used, and the MPR logo and project number were printed in color on the upper left portion of the envelope. Also a "live" first-class stamp was used instead of the cheaper bulk rate insignia that is common to many forms of bulk mailing. 
For the Baseline Survey, the welcome packets were sent in four separate mailings, as shown in Table 9. Updated address information was downloaded from the KFS questionnaire into the SMS and used to create an updated address file for these mailings.

\section{TABLE 9}

\section{KAUFFMAN FIRM SURVEY WELCOME PACKET MAILINGS BY DATE}

\begin{tabular}{lrc}
\hline Date Mailed & Quantity & Period Covered \\
\hline $1 / 28 / 2006$ & 2,500 & $6 / 15 / 2005$ to $1 / 17 / 2006$ \\
$2 / 21 / 2006$ & 700 & $1 / 18 / 2006$ to $2 / 16 / 2006$ \\
$5 / 30 / 2006$ & 1,370 & $2 / 17 / 2006$ to $5 / 23 / 2006$ \\
$8 / 1 / 2006$ & 358 & $5 / 24 / 2006$ to $7 / 31 / 2006$ \\
\hline
\end{tabular}

Effectiveness of the Welcome Packet. The welcome packet proved to be an effective tool in getting updated contact information. Of the 4,928 packets sent, 128 packets (2.6 percent) were returned from the post office as undeliverable. The returned packets were sent to MPR's locating department where additional research was done to find the new locations of the businesses. New addresses were found for 89 (70 percent) of those businesses, and the welcome packet was resent to the updated addresses.

Sending the welcome packets also proved to be a valuable vehicle that reminded sample members about the $\$ 50$ incentive. Upon receiving the welcome packet, many called in to say that the $\$ 50$ incentive had not been received, and MPR staff was able to verify through the respondent payment system that the checks were sent but never cashed. Any missing address information, most commonly a missing suite or apartment number, was collected and updated in the SMS, and the checks were reissued. This updated contact information was collected and stored for use on follow-up surveys. 


\section{F. CODING AND DATA PROCESSING}

\section{Back Coding}

Fifteen questions in the KFS Baseline questionnaire contained open-ended responses, with all but one being an "Other-Specify" alternative if respondents did not think their responses fit into one of the existing answer categories. Each of these responses was typed verbatim by the interviewer (or by the respondent if he or she responded via the web survey), and these responses were reviewed for opportunities for back coding. Back coding is the process of determining if the respondent's answer does actually fit into one of the existing answer categories. Sometimes respondents may not hear all of the answer categories during a telephone interview, may not read them carefully if doing a web survey, or may interpret an answer category differently than intended. Although some of these responses could not be back coded into an already existing response category, many could. Qualified and experienced coding staff performed the back coding of the "Other-Specify" responses collected at the following questions:

- A10 (Reason for being out of business)

- B1g (How the business was started)

- B2 (Form of legal status of business)

- C8 (Primary location where business operates)

- E1h (Key responsibilities of employees)

- E2a.1 (Employee benefits provided to full-time employees)

- E2b.1 (Employee benefits provided to part-time employees)

- F3g (Sources of equity)

- F7f (Sources of Baseline respondent debt)

- F9f (Sources of other owner debt)

- F11k (Sources of debt of the business)

- F28g (Other business owner property) 
- F28h (Other assets)

- F30c (Other liabilities)

- G6 (Race)

Four separate rounds of coding work were performed. The first three rounds were done on completed cases while the Baseline data collection was still underway. This procedure was followed in order to complete the coding work on a flow basis and avoid bottlenecks in the process of readying cases for the KFS First Follow-Up Survey. Some data from the Baseline interviews were used as inputs for the First Follow-Up (including the business industry codes and descriptions, as well as the description of the legal status of the business), meaning that the Baseline back coding had to be completed for these cases to be available for release in the First Follow-Up.

\section{Industry Coding}

Question C1b (principal activity of the business) is used to determine the North American Industry Classification System (NAICS) code of the business. The NAICS system was developed by the U.S. Census Bureau and is the standard establishment classification for all federal surveys, replacing the Standard Industry Classification (SIC) codes. The Baseline interview provided the industry description listed in the D\&B record for the business and asked sample members if that information was correct. If the sample member disagreed with the business description, the interviewer asked for a description and recorded what the sample member said verbatim. Coders then reviewed these descriptions and attempted to code them to a NAICS code. MPR used coders with substantial experience in industry and, specifically, NAICS coding, and they were instructed to leave the six-digit code provided from D\&B if they could not code to a six-digit NAICS based on the description. 
The next step was to ensure that the NAICS descriptions for the updated NAICS code were entered into the case records. This required getting the listing of NAICS codes and associated descriptions, matching them to the cases with back coded NAICS codes, and inserting the matching description into the case. This description was then preloaded into the First Follow-Up instrument as the description of the principal activity of the business.

\section{Financial Data Coding}

Financial data back coding presented a number of challenges. Not all new business owners have a clear understanding of financial accounting, asset categories, or the difference between debt and equity.

Because the items in the business finances section included dollar values, back coding the items also required adding the amount of the back coded item to the appropriate response category. For example, if a respondent indicated in the "Other-Specify" for equity investment that "Dad" had invested $\$ 10,000$ in the business, the $\$ 10,000$ would have to be added to any amount already entered into the section that recorded amounts invested by "parents, in-laws, or children of owners of the business." Many of the financial back codes were obvious after review by project staff and could be programmed. MPR programmers developed programs that would move the back coded items from the "Other-Specify" field into the correct response category and add the related dollar amount into the proper field. This allowed the item and the corresponding amount of the item to be back coded to the appropriate category.

Other items were somewhat more complex. For example, many respondents did not make a clear distinction between the two "Other Asset" categories at Question F28, and these had to be adjusted as well. "Any other business property" (F28g) was designed to capture tangible assets such as airplanes, while the "Any other assets" category (F28h) was designed to capture 
intangible assets such as patents, trademarks and copyrights, as well as financial assets such as long-term bonds.

Some of the "Other-Specify" fields required more extensive review and case-by-case recoding. In some cases, account balances had to be moved from debt to equity and vice versa. When in doubt, the respondent's entries were left as is, but when it was clear that the respondent had put an account in the wrong place, appropriate adjustments were made directly into the case.

\section{Quality Assurance}

Quality assurance (QA) is part of the MPR approach to all survey work, and this was also true throughout the coding process. The coding supervisor reviewed all work completed by coders and made corrections before sending the output to project staff, who, in turn, performed QA. Project staff members would comment on any cases that they changed so that the coders would have feedback for future rounds of coding. These were primarily reminders about procedures for handling responses that could not be back coded.

MPR programmers tested all back coding programs on a test data set for accuracy. Both the programming and project staffs examined the adjusted data set to make sure that all changes were made accurately. Each step of the process was documented and culminated in the examination of the actual data set. As previously mentioned, the NAICS coding description and six-digit code had to be inserted into the CATI program for the First Follow-Up Survey. Both were checked to ensure that these new descriptions got into the interview preloads accurately. Additional checks were made to assure that back coded financial items and their associated amounts had been properly transferred.

Project staff also looked for common "Other-Specify" answers to any question, in order to determine if that response should be added as a response category in the First Follow-Up. If any response to an "Other-Specify" category appeared in 3 percent or more of the cases, 
consideration would be given to adding the response category. No question, however, had an "Other-Specify" response that reached this threshold.

\section{Frequency Review}

Upon completion of the data collection and coding, the full list of variables in the raw data file was provided to the project staff. The list was reviewed, and those variables needed for the analysis were provided to MPR programmers to include in the frequencies. A number of variables were not included in the analysis, such as those MPR created to help manage the data collection, as well as variables that would identify businesses or owners. The frequencies were then run on those variables that were to be included in the final data file.

The main functions of reviewing the raw data through frequencies are to check that the routing of the instrument was working properly and to check for data values that were inconsistent. As mentioned earlier, the web and CATI surveys included edit and consistency checking, although the number of these checks varied between the two modes. The checks in the CATI were more extensive, whereas the web survey was designed to balance between the need to collect complete and consistent data and the desire to avoid increasing respondent frustration resulting in higher numbers of web break offs. As a result, cases completed on the web contained more instances of inconsistent data because of fewer built-in checks. During the initial review of the frequencies, any inconsistent values or routing problems were noted for cleaning during the data editing stage. The frequency review also served as a final check that "OtherSpecify" responses were back coded properly, with any additional responses that could be back

coded noted so that these could be fixed during the editing stage. After review of the frequencies, we compiled a list of values to be edited and began constructing a set of cleaning specifications to be implemented through SAS. 


\section{Data Cleaning}

The goal of the Baseline data cleaning process was to create a set of specifications that would be programmed into SAS and used to machine-edit the Baseline data. We also produced the data cleaning specifications with future follow-up surveys in mind, to decrease the time and effort needed to complete the data cleaning during future rounds. The specifications for these computer edits began by using the existing skip patterns and consistency checks in the CATI questionnaire, and these were then expanded to cover other data consistency issues detected during the initial frequency review.

As previously discussed, not all skip patterns and consistency checks included in the CATI instrument were part of the web instrument, so these cleaning rules needed to be made explicit in order to produce one consistent data set across the two modes. The cleaning steps were provided to MPR programmers in the form of "if/then" statements. Many of these edit statements were designed to clean data when a skip pattern was working correctly, but the resulting data were inconsistent. For instance, if a web respondent indicated that the business had a patent but entered a "0" for the number of patents (question D3a), the cleaning statement would clean the response to the first question from "Yes" to "No" and blank the numerical value at the second question. Another function of the cleaning statements was to produce a clean version of data for questions that respondents had to correct. For instance, when respondents were asked the question about the percentage of sales to different types of customers (question D7), the respondent was asked to correct the responses if the original percentages did not add to 100 percent. These corrected responses were placed in a separate variable, so cleaning steps were put in place to ensure that information from the corrected variable was placed as the final value for cases asked to correct their data. 
After these cleaning statements were finalized, they were programmed into SAS and run on the raw data file. The SAS programmer also cleaned the individual data problems catalogued during the review of the frequencies discussed in the previous section. After these processes were completed, a second set of frequencies was run on the clean file, and these went through a second round of quality control review by project staff to ensure that the cleaning statements were implemented properly and any other data inconsistencies were cleaned.

\section{Constructed Variables}

The KFS instruments asked many measures at different levels of specificity, especially at questions in the business finances section. For this reason, the KFS project team created a set of constructed variables so that data collected through different questions could be combined to make analysis of these data easier. These constructed variables fell into several categories.

\section{a. Financial Measures with Three Levels of Data}

When asked about different sources of business financing, such as equity or debt, respondents were first asked if these sources were used (an "indicator" question). Respondents reporting the business had used one of these types of financing were then asked for an exact dollar amount for the reference period. Respondents unable or unwilling to provide an exact dollar amount (either through a "don't know" or "refused" response in CATI or by leaving the field blank on the web) were provided a set of ranges and asked to select the appropriate range. The goal of constructing variables for these financial measures was to combine these values into one variable that would provide researchers with both the incidence of usage and information on the amounts used or acquired during the reference period. Respondents answering "no" to the indicator question were given a " 0 " in the constructed variable. For exact value responses, the value associated with the range the value fell into was placed in the new constructed variable. 
For example, if a respondent indicated the business had a year-end personal credit card balance of $\$ 20,000$ (question F8b), the value "6" was placed in the constructed variable, indicating the range $\$ 10,001$ to $\$ 25,000$. For respondents who gave a range response to the question, these values were placed in the constructed variable as is.

\section{b. Financial Variables with Two Levels of Data}

Constructed variables were also created for measures that did not include an indicator variable, such as total expenses (F17) and total wage expenses (F18). For these constructed variables, the same process of translating the exact values into ranges was followed.

\section{c. Variables Summing Financial Measures}

The KFS instrument asked about equity and debt in terms of specific sources, such as from owner-operators, family members, banks, and other organizations. A set of constructed variables was created that provided subtotals of equity and debt provided by owner-operators and nonowner-operators, as well as a total from all sources. These were created by summing all discrete sources falling into a particular category.

\section{d. Intellectual Property Measures}

The KFS questions on patents, copyrights, and trademarks asked an indicator question for each type, and businesses that reported having these types of properties were asked how many they had. The constructed variables were created to provide both the incidence and quantities of the these items by entering a " 0 " for cases reporting no patents, copyrights, or trademarks, and for those reporting them, the number of the specific type was entered into the constructed variable.

A full list of the variables constructed for the KFS Baseline Survey data file and more information about their construction are available in the data documentation memo, which is 
included as Appendix $\mathrm{H}$ of this report. Once the constructed variables were created and quality control was performed on them, the clean data file was provided to MPR statisticians so that the survey weights and nonresponse adjustment variables could be added to the file.

\section{Preparation of Codebook and Data Documentation}

The main codebook for the KFS is the questionnaire, which was annotated to include the variable names in the data file next to the appropriate questions from which the variables were derived. The annotated questionnaire is included as Appendix I of this report. As previously mentioned, a data documentation memo was also prepared, which provides information about variables not derived from the questionnaire, including

- Sampling variables, such as those used in the explicit (technology) and implicit (gender) strata

- Weighting variables, such as nonresponse and poststratification adjustments as well as the total weight variable

- Survey management variables, such as the unique identification number given to cases, final dispositions, number of contacts made to businesses, and so on

- D\&B derived variables, such as industry codes and other descriptive measures provided with the D\&B file

- Constructed variables, as discussed earlier.

\section{G. WEIGHTING AND NONRESPONSE ADJUSTMENTS}

\section{Response Analysis Summary}

For the purpose of nonresponse analysis and weighting, the 32,469 cases fielded during the Baseline Survey were classified into two categories: located cases and unlocated cases. Then among all located cases, the businesses were classified into two further groups: completes and nonrespondents. Completes include completed interviews and ineligible businesses for which complete data were obtained. We separated the location and response status because the businesses that we were more likely to locate were not necessarily the businesses that were more 
likely to respond to the survey. The weighted location and response rates for the full sample are given in Table 10 and by technology stratum in Tables 11 to 13.

In general, businesses in the high-tech and medium-tech sampling strata responded at a higher rate than did non-tech businesses. In additional to the technology sampling strata, we investigated the response patterns by gender of the principal owner (based on a modified versions of the woman-ownership flag in the D\&B database), geography (using the Census regions and whether the business was located in a metropolitan statistical area (MSA), and the number of employees reported by D\&B. Businesses in the Midwest census region responded at a higher rate across all strata, but businesses in the high-tech sampling stratum in the Northeast also had a high response rate. Woman-owned businesses and businesses outside of MSAs responded at a higher rate, but the differential was smaller among businesses in the high-tech sampling stratum for both of these characteristics. Businesses with D\&B data indicating no employees or only one employee had higher response rates than larger businesses, but again the differential was smaller in the businesses in the high-tech sampling stratum. 
TABLE 10

WEIGHTED LOCATION AND RESPONSE RATES AMONG BUSINESSES IN THE KAUFFMAN FIRM SURVEY

\begin{tabular}{|c|c|c|c|c|c|c|}
\hline & $\begin{array}{l}\text { Sample } \\
\text { Count }\end{array}$ & Located & $\begin{array}{l}\text { Weighted } \\
\text { Percentage } \\
\text { Located }\end{array}$ & Completes $^{\mathrm{a}}$ & $\begin{array}{c}\text { Weighted } \\
\text { Percentage } \\
\text { Complete/ } \\
\text { Located }\end{array}$ & $\begin{array}{c}\text { AAPOR } \\
\text { Weighted } \\
\text { Response } \\
\text { Rate }\end{array}$ \\
\hline \multicolumn{7}{|l|}{ High-Tech Sampling Strata } \\
\hline High-Tech & 3,869 & 3,640 & 94.1 & 2,051 & 56.3 & 46.3 \\
\hline Medium-Tech & 7,574 & 6,839 & 90.3 & 4,010 & 58.8 & 48.6 \\
\hline Non-Tech & 21,026 & 19,047 & 90.7 & 10,095 & 53.5 & 41.6 \\
\hline \multicolumn{7}{|l|}{ Woman Ownership } \\
\hline Woman-owned & 4,553 & 4,150 & 91.4 & 2,505 & 59.7 & 48.8 \\
\hline Non-woman-owned & 27,916 & 25,376 & 90.5 & 13,651 & 52.8 & 41.0 \\
\hline \multicolumn{7}{|l|}{ D\&B Employee Count } \\
\hline $0-1$ & 13,590 & 12,164 & 89.4 & 6,935 & 56.4 & 44.6 \\
\hline $2-4$ & 13,424 & 12,241 & 91.0 & 6,631 & 53.7 & 42.3 \\
\hline $5+$ & 5,455 & 5,121 & 93.5 & 2,590 & 49.5 & 37.4 \\
\hline \multicolumn{7}{|c|}{$\begin{array}{l}\text { Metropolitan Statistical Area } \\
\text { (MSA) }\end{array}$} \\
\hline Not in MSA & 4,445 & 4,119 & 92.5 & 2,528 & 61.1 & 49.8 \\
\hline In MSA & 28,024 & 25,407 & 90.4 & 13,628 & 52.9 & 41.3 \\
\hline \multicolumn{7}{|l|}{ Census Division } \\
\hline Midwest & 6,587 & 6,090 & 92.0 & 3,565 & 58.1 & 47.2 \\
\hline Northeast & 5,272 & 4,822 & 91.0 & 2,562 & 51.7 & 41.0 \\
\hline South & 12,288 & 11,033 & 89.6 & 5,968 & 53.7 & 40.8 \\
\hline West & 8,322 & 7,581 & 91.0 & 4,061 & 53.1 & 42.2 \\
\hline \multicolumn{7}{|l|}{ Urbanicity Code } \\
\hline \multicolumn{7}{|l|}{ Metro areas with at } \\
\hline \multicolumn{7}{|l|}{$\begin{array}{l}\text { Metro areas with } \\
\text { fewer than } 1 \text { million }\end{array}$} \\
\hline residents & 8,810 & 8,085 & 91.5 & 4,548 & 55.4 & 44.4 \\
\hline Remaining & 4,226 & 3,937 & 93.2 & 2,550 & 65.1 & 52.9 \\
\hline $\begin{array}{l}\text { Woman Ownership } \\
\text { Sampling Stratum by D\&B }\end{array}$ & & & & & & \\
\hline $0-1$ & 2,136 & 1,911 & 89.2 & 1,206 & 61.9 & 49.7 \\
\hline $2-4$ & 1,735 & 1,608 & 93.2 & 952 & 59.0 & 49.4 \\
\hline $5+$ & 682 & 631 & 93.2 & 347 & 54.8 & 44.1 \\
\hline \multicolumn{7}{|c|}{$\begin{array}{l}\text { Man Ownership Sampling } \\
\text { Stratum by D\&B Employee } \\
\text { Count }\end{array}$} \\
\hline $0-1$ & 11,454 & 10,253 & 89.4 & 5,729 & 54.9 & 43.2 \\
\hline $2-4$ & 11,689 & 10,633 & 90.5 & 5,679 & 52.5 & 40.7 \\
\hline $5+$ & 4,773 & 4,490 & 93.5 & 2,243 & 48.3 & 35.9 \\
\hline All & 32,469 & 29,526 & 90.7 & 16,156 & 54.2 & 42.5 \\
\hline
\end{tabular}

${ }^{\text {a }}$ Completed cases include businesses with complete data for applicable questions. These include eligible and ineligible completes.

Note: D\&B data were from data records used for the sample selection and do not purport to be current data. 
TABLE 11

WEIGHTED LOCATION AND RESPONSE RATES AMONG BUSINESSES IN THE KAUFFMAN FIRM SURVEY: HIGH-TECH

\begin{tabular}{|c|c|c|c|c|c|c|}
\hline & $\begin{array}{c}\text { Sample } \\
\text { Count }\end{array}$ & Located & $\begin{array}{l}\text { Weighted } \\
\text { Percentage } \\
\text { Located }\end{array}$ & Completes $^{\mathrm{a}}$ & $\begin{array}{c}\text { Weighted } \\
\text { Percentage } \\
\text { Complete/ } \\
\text { Located }\end{array}$ & $\begin{array}{c}\text { AAPOR } \\
\text { Weighted } \\
\text { Response Rate }\end{array}$ \\
\hline \multicolumn{7}{|l|}{ Census Division } \\
\hline Midwest & 841 & 797 & 94.8 & 473 & 59.3 & 50.9 \\
\hline Northeast & 655 & 623 & 95.1 & 375 & 60.2 & 50.3 \\
\hline South & 1,240 & 1,167 & 94.1 & 646 & 55.4 & 43.3 \\
\hline West & 1,133 & 1,053 & 92.9 & 557 & 52.9 & 43.6 \\
\hline \multicolumn{7}{|l|}{ Woman Ownership } \\
\hline Woman-owned & 527 & 491 & 93.2 & 287 & 58.5 & 48.3 \\
\hline Non-woman-owned & 3,342 & 3,149 & 94.2 & 1,764 & 56.0 & 46.0 \\
\hline \multicolumn{7}{|l|}{$\begin{array}{l}\text { Metropolitan Statistical Area } \\
\text { (MSA) }\end{array}$} \\
\hline Not in MSA & 538 & 514 & 95.5 & 310 & 60.3 & 51.4 \\
\hline In MSA & 3,331 & 3,126 & 93.8 & 1,741 & 55.7 & 45.4 \\
\hline \multicolumn{7}{|l|}{ Population (County) } \\
\hline Less than 100,000 & 696 & 661 & 95.0 & 405 & 61.3 & 52.4 \\
\hline $100,000-500,000$ & 1,121 & 1,075 & 95.9 & 630 & 58.6 & 48.5 \\
\hline 500,000 or more & 2,052 & 1,904 & 92.8 & 1,016 & 53.4 & 42.9 \\
\hline \multicolumn{7}{|l|}{ D\&B Employee Count } \\
\hline $0-1$ & 1,047 & 952 & 90.9 & 536 & 56.3 & 46.2 \\
\hline $2-4$ & 1,552 & 1,462 & 94.2 & 848 & 58.0 & 48.8 \\
\hline $5+$ & 1,270 & 1,226 & 96.5 & 667 & 54.4 & 42.7 \\
\hline \multicolumn{7}{|l|}{ Legal Status (D\&B data) } \\
\hline Unknown/Unavailable & 1,101 & 1,012 & 91.9 & 555 & 54.8 & 43.0 \\
\hline Corporation & 1,542 & 1,481 & 96.0 & 849 & 57.3 & 47.7 \\
\hline Partnership & 588 & 570 & 96.9 & 319 & 56.0 & 47.5 \\
\hline Proprietorship & 638 & 577 & 90.4 & 328 & 56.8 & 47.4 \\
\hline \multicolumn{7}{|l|}{ Sales Volume (D\&B Data) } \\
\hline Less than $\$ 100,000$ & 1,012 & 916 & 90.5 & 524 & 57.2 & 46.8 \\
\hline$\$ 100,000-\$ 199,999$ & 880 & 827 & 94.0 & 450 & 54.4 & 44.9 \\
\hline$\$ 200,000-\$ 999,999$ & 1,198 & 1,140 & 95.2 & 692 & 60.7 & 51.7 \\
\hline$\$ 1,000,000$ or more & 779 & 757 & 97.2 & 385 & 50.9 & 37.6 \\
\hline All & 3,869 & 3,640 & 94.1 & 2,051 & 56.3 & 46.3 \\
\hline
\end{tabular}

${ }^{\text {a }}$ Completed cases include businesses with complete data for applicable questions. These include eligible and ineligible completes.

Note: D\&B data were from data records used for the sample selection and do not purport to be current data. 
TABLE 12

WEIGHTED LOCATION AND RESPONSE RATES AMONG BUSINESSES IN THE KAUFFMAN FIRM SURVEY: MEDIUM-TECH

\begin{tabular}{|c|c|c|c|c|c|c|}
\hline & $\begin{array}{l}\text { Sample } \\
\text { Count }\end{array}$ & Located & $\begin{array}{c}\text { Weighted } \\
\text { Percentage } \\
\text { Located }\end{array}$ & Completes $^{\mathrm{a}}$ & $\begin{array}{c}\text { Weighted } \\
\text { Percentage } \\
\text { Complete/ } \\
\text { Located }\end{array}$ & $\begin{array}{c}\text { AAPOR } \\
\text { Weighted } \\
\text { Response Rate } \\
\end{array}$ \\
\hline \multicolumn{7}{|l|}{ Census Division } \\
\hline Midwest & 1,444 & 1,334 & 92.4 & 833 & 62.6 & 54.5 \\
\hline Northeast & 1,275 & 1,171 & 91.8 & 677 & 58.1 & 47.7 \\
\hline South & 2,859 & 2,538 & 88.8 & 1,448 & 57.1 & 46.3 \\
\hline West & 1,996 & 1,796 & 89.9 & 1,052 & 58.8 & 47.9 \\
\hline \multicolumn{7}{|c|}{ Woman Ownership Sampling Stratum } \\
\hline Woman-owned & 1,266 & 1,132 & 89.6 & 722 & 63.8 & 53.7 \\
\hline Non-woman-owned & 6,308 & 5,707 & 90.5 & 3,288 & 57.6 & 47.4 \\
\hline \multicolumn{7}{|l|}{$\begin{array}{l}\text { Metropolitan Statistical Area } \\
\text { (MSA) }\end{array}$} \\
\hline Not in MSA & 722 & 656 & 90.9 & 440 & 67.2 & 57.3 \\
\hline In MSA & 6,852 & 6,183 & 90.3 & 3,570 & 57.9 & 47.7 \\
\hline \multicolumn{7}{|l|}{ Population (County) } \\
\hline Less than 100,000 & 983 & 898 & 91.4 & 593 & 66.2 & 56.9 \\
\hline $100,000-500,000$ & 2,373 & 2,164 & 91.2 & 1,303 & 60.2 & 51.3 \\
\hline 500,000 or more & 4,218 & 3,777 & 89.6 & 2,114 & 56.2 & 45.0 \\
\hline \multicolumn{7}{|l|}{ D\&B Employee Count } \\
\hline $0-1$ & 4,222 & 3,777 & 89.5 & 2,320 & 61.6 & 51.5 \\
\hline $2-4$ & 2,196 & 2,002 & 91.1 & 1,140 & 57.0 & 46.6 \\
\hline $5+$ & 1,156 & 1,060 & 91.7 & 550 & 52.1 & 41.6 \\
\hline \multicolumn{7}{|l|}{ Legal Status (D\&B data) } \\
\hline Unknown/Unavailable & 3,510 & 3,126 & 89.1 & 1,846 & 59.2 & 47.9 \\
\hline Corporation & 2,158 & 1,974 & 91.5 & 1,087 & 55.1 & 45.7 \\
\hline Partnership & 697 & 646 & 92.6 & 366 & 56.8 & 48.6 \\
\hline Proprietorship & 1,209 & 1,093 & 90.4 & 711 & 65.3 & 55.8 \\
\hline \multicolumn{7}{|l|}{ Sales Volume (D\&B Data) } \\
\hline Less than $\$ 50,000$ & 1,735 & 1,507 & 86.9 & 906 & 60.3 & 48.5 \\
\hline$\$ 50,000-\$ 99,999$ & 2,571 & 2,333 & 90.8 & 1,456 & 62.6 & 53.7 \\
\hline$\$ 100,000-\$ 199,999$ & 1,431 & 1,312 & 91.7 & 737 & 56.2 & 46.0 \\
\hline$\$ 200,000$ or more & 1,837 & 1,687 & 91.8 & 911 & 54.1 & 43.5 \\
\hline All & 7,574 & 6,839 & 90.3 & 4,010 & 58.8 & 48.6 \\
\hline
\end{tabular}

${ }^{\text {a }}$ Completed cases include businesses with complete data for applicable questions. These include eligible and ineligible completes.

Note: D\&B data were from data records used for the sample selection and do not purport to be current data. 
TABLE 13

WEIGHTED LOCATION AND RESPONSE RATES AMONG BUSINESSES IN THE KAUFFMAN FIRM SURVEY: NON-TECH

\begin{tabular}{|c|c|c|c|c|c|c|}
\hline & $\begin{array}{l}\text { Sample } \\
\text { Count }\end{array}$ & Located & $\begin{array}{c}\text { Weighted } \\
\text { Percentage } \\
\text { Located } \\
\end{array}$ & Completes $^{\mathrm{a}}$ & $\begin{array}{l}\text { Weighted } \\
\text { Percentage } \\
\text { Complete/ } \\
\text { Located } \\
\end{array}$ & $\begin{array}{c}\text { AAPOR } \\
\text { Weighted } \\
\text { Response } \\
\text { Rate } \\
\end{array}$ \\
\hline \multicolumn{7}{|l|}{ Census Division } \\
\hline Midwest & 4,302 & 3,959 & 92.0 & 2,259 & 58.0 & 46.1 \\
\hline Northeast & 3,342 & 3,028 & 90.8 & 1,510 & 50.6 & 39.9 \\
\hline South & 8,189 & 7,328 & 89.6 & 3,874 & 53.2 & 39.9 \\
\hline West & 5,193 & 4,732 & 91.2 & 2,452 & 52.3 & 41.4 \\
\hline \multicolumn{7}{|c|}{ Woman Ownership Sampling Stratum } \\
\hline Woman-owned & 2,760 & 2,527 & 91.6 & 1,496 & 59.2 & 48.2 \\
\hline Non-woman-owned & 18,266 & 16,520 & 90.4 & 8,599 & 52.1 & 40.0 \\
\hline \multicolumn{7}{|l|}{$\begin{array}{l}\text { Metropolitan Statistical Area } \\
\text { (MSA) }\end{array}$} \\
\hline Not in MSA & 3,185 & 2,949 & 92.6 & 1,778 & 60.6 & 49.1 \\
\hline In MSA & 17,841 & 16,098 & 90.3 & 8,317 & 52.2 & 40.2 \\
\hline \multicolumn{7}{|l|}{ Population (County) } \\
\hline Less than 100,000 & 4,127 & 3,809 & 92.4 & 2,262 & 59.8 & 48.4 \\
\hline $100,000-500,000$ & 6,672 & 6,118 & 91.7 & 3,328 & 54.9 & 44.1 \\
\hline 500,000 or more & 10,227 & 9,120 & 89.3 & 4,505 & 49.8 & 37.1 \\
\hline \multicolumn{7}{|l|}{ D\&B Employee Count } \\
\hline $0-1$ & 8,321 & 7,435 & 89.3 & 4,079 & 55.4 & 43.2 \\
\hline 2 & 9,676 & 8,777 & 90.9 & 4,643 & 53.4 & 41.8 \\
\hline $3+$ & 3,029 & 2,835 & 93.6 & 1,373 & 48.9 & 36.6 \\
\hline \multicolumn{7}{|l|}{ Legal Status (D\&B Data) } \\
\hline Unknown/Unavailable & 11,215 & 10,008 & 89.3 & 5,270 & 53.1 & 40.8 \\
\hline Corporation & 4,890 & 4,511 & 92.3 & 2,413 & 53.9 & 41.9 \\
\hline Partnership & 1,729 & 1,624 & 94.0 & 806 & 50.0 & 41.1 \\
\hline Proprietorship & 3,192 & 2,904 & 91.0 & 1,606 & 55.9 & 44.5 \\
\hline \multicolumn{7}{|l|}{ Sales Volume (D\&B Data) } \\
\hline Less than $\$ 50,000$ & 4,800 & 4,300 & 89.6 & 2,391 & 56.1 & 43.7 \\
\hline$\$ 50,000-\$ 99,999$ & 5,479 & 4,869 & 89.0 & 2,648 & 54.8 & 42.0 \\
\hline$\$ 100,000-\$ 199,999$ & 5,152 & 4,694 & 91.2 & 2,463 & 53.0 & 42.2 \\
\hline$\$ 200,000$ or more & 5,595 & 5,184 & 92.7 & 2,593 & 50.4 & 39.0 \\
\hline All & 21,026 & 19,047 & 90.7 & 10,095 & 53.5 & 41.6 \\
\hline
\end{tabular}

${ }^{\text {a }}$ Completed cases include businesses with complete data for applicable questions. These include eligible and ineligible completes.

Note: D\&B data were from data records used for the sample selection and do not purport to be current data. 


\section{Sampling Weights}

The initial sampling weight is defined as the inverse of the probability of selection. The weight is calculated within the technology group and the woman-owned status, as well as within the two sampling frame files we received from D\&B (June 2005, November 2005) separately. Table 14 shows the initial sampling weights.

TABLE 14

INITIAL SAMPLING WEIGHTS

\begin{tabular}{lcccc}
\hline & $\begin{array}{c}\text { June } \\
\text { Woman- } \\
\text { Ownership }\end{array}$ & $\begin{array}{c}\text { November } \\
\text { Woman- } \\
\text { Ownership } \\
\text { Technology Sampling } \\
\text { Stratum }\end{array}$ & $\begin{array}{c}\text { June } \\
\text { Man- } \\
\text { Ownership } \\
\text { Sampling Strata } \\
\text { Sampling Strata }\end{array}$ & $\begin{array}{c}\text { November } \\
\text { Man- } \\
\text { Ownership } \\
\text { Sampling } \\
\text { Strata }\end{array}$ \\
\hline High-Tech & 1 & 1 & 1 & 1 \\
Medium-Tech & 4.21 & 5.11 & 3.84 & 3.77 \\
Non-Tech & 15.32 & 14.85 & 9.72 & 9.35 \\
\hline
\end{tabular}

\section{Nonresponse Adjustment}

In essentially all surveys, the sampling weights need to be adjusted to compensate for the sample members who cannot be located or refuse to respond. A commonly used method to compute weight adjustments is to form classes of sample members with similar characteristics and to use the inverse of the class response rate as the adjustment factor in that class. The adjusted weight is the product of the sampling weight and the adjustment factor. The weighting classes are formed to ensure sufficient counts in each class to make the adjustment more stable (that is, to have a smaller variance). The weighting class procedure is comparable to the use of logistic regression with the weighting class definitions as covariates. The logistic regression 
approach also has the ability to include both continuous and categorical variables, and standard statistical tests are available to evaluate the selection of variables for the model.

For the KFS nonresponse adjustments to the sampling weights, we used weighted logistic propensity modeling separately for each technology stratum and for location and response among the located sample, meaning a total of six response propensity logistic models were created. For each "propensity to locate" model, we fitted the model to a binary response indicator of whether or not the sample member could be located. The inverse of the propensity score was used as the location adjustment factor. The location-adjusted weight for each sample case is the product of the initial sampling weight and the location adjustment factor. For the propensity to respond among located businesses, we repeated this modeling process among respondents who were located, and another weighted logistic regression model was fitted. The two levels in the binary response for this model were "respondent" versus "nonrespondent" among located businesses. For the KFS, a sample member was classified as a respondent if the sample member completed the interview (that is, was an eligible respondent) or the sample member was determined to be ineligible (that is, was an ineligible respondent). The inverse of the propensity score this time was used as the response adjustment factor. The response-adjusted weight for each sample case is the product of the location-adjusted weight and the response adjustment factor. Finally, a poststratification factor was computed in each technology group to ensure that the sum of the final weight equals the number of businesses in the population.

The models were developed using the main effects, plus selected interactions. To identify candidate independent variables and interactions among these variables for the modeling, we first ran a chi-squared automatic interaction detector (CHAID) analysis in SPSS to find possible 
significant predictors. CHAID is normally attributed to Kass $(1980)^{8}$ and Biggs et al. (1991), ${ }^{9}$ and its application in SPSS is described in Magidson (1993). ${ }^{10}$ The CHAID procedure iteratively segments a data set into mutually exclusive subgroups that share similar characteristics based on their effect on nominal or ordinal dependent variables. It automatically checks all variables in the data set and creates a hierarchy that shows all statistically significant subgroups. The algorithm finds splits in the population, which are as different as possible based on a chi-square statistic. It is a forward stepwise procedure, and it finds the most diverse subgrouping, and then each of these subgroups is further split into more diverse sub-subgroups. Sample size limitations are set to avoid generating cells with small counts. The process stops when splits are no longer significant; that is, that group is homogeneous with respect to variables not yet used or the cells contain too few cases. The CHAID procedure results in a tree that identifies the set of variables and interactions among the variables that have an association with the ability to locate a sample member (and the propensity of a located sample member to either respond or be ineligible).

The variables and interactions identified using CHAID were then processed using forward and backward stepwise regression (using the SAS Logistic procedure with weights normalized to the sample size) to further refine the candidate variables and interaction terms. After identifying a smaller pool of main effects and interactions for potential inclusion in the final model, a set of models was carefully evaluated to determine the final model. Because the SAS logistic procedure does not incorporate the sampling design, the final selection of the covariates was

\footnotetext{
${ }^{8}$ G. V. Kass, "An Exploratory Technique for Investigating Large Quantities of Categorical Data," Applied Statistics 29 (1980): 119-127.

${ }^{9}$ D. Biggs, B. de Ville, and E. Suen, "A Method of Choosing Multiway Partitions for Classification and Decision Trees," Journal of Applied Statistics 18 (1991): 49-62.

${ }^{10}$ J. Magidson, SPSS for Windows CHAID Release 6.0. (Belmont MA: Statistical Innovations, 1993).
} 
accomplished with the logistic regression procedure in SUDAAN ${ }^{11}$ using various measures of goodness of fit and predictive ability.

For selecting variables or interactions in a model, we included variables or interactions that have a statistical significance level (alpha level) of 0.30 or lower (instead of the standard 0.05). We used a higher significance level because the purpose of the model was to improve the estimation of the propensity score and not to identify statistically significant factors related to response. In addition, the information sometimes reflected proxy variables for some underlying variable that was both unknown and unmeasured. The analysis of the location and response patterns showed considerable interactive effects. Three-order and four-order interactions were common and were difficult to interpret. The variables used as main effects and the interaction in the model are summarized in Table 15 for locating a sample member and in Table 16 for cooperation among located sample members. The R-square ranges from 0.02 to 0.04 for the various models, and the Hosmer-Lemeshow (H-L) statistics range from 0.49 to 0.98 . These values are similar to those observed for other response propensity modeling efforts using logistic regression with design-based sampling weights.

${ }^{11}$ Research Triangle Institute, SUDAAN Language Manual, Release 9.0 (Research Triangle Park, NC: Research Triangle Institute, 2004). 
TABLE 15

SUMMARY OF LOCATION MODELS

\begin{tabular}{|c|c|c|c|c|}
\hline Variable & Level & High-Tech & Medium-Tech & Non-Tech \\
\hline $\begin{array}{l}\text { Census division } \\
\text { Sales volume (D\&B }\end{array}$ & 4 & Main, Interaction & Interaction & Interaction \\
\hline Data) & 4 & Main, Interaction & Main, Interaction & Main, Interaction \\
\hline Population size & 3 & Main, Interaction & Main, Interaction & Interaction \\
\hline Own/Rent (D\&B Data) & 2 & Main & Interaction & Interaction \\
\hline \multicolumn{5}{|l|}{ Legal status (D\&B } \\
\hline Data) & 4 & Main, Interaction & Main, Interaction & Main, Interaction \\
\hline D\&B Employee Count & 3 & Interaction & Interaction & Interaction \\
\hline \multicolumn{5}{|l|}{ Metropolitan Statistical } \\
\hline Area (MSA) & 2 & Interaction & & \\
\hline Woman-ownership & 2 & Main, Interaction & & Main, Interaction \\
\hline Major industry & 5 & & & Interaction \\
\hline Small business & 2 & & & Main, Interaction \\
\hline Full R-square & & 0.0389 & 0.0198 & 0.0155 \\
\hline Reduced R-square & & 0.0352 & 0.0181 & 0.0140 \\
\hline \multicolumn{5}{|l|}{ Hosmer-Lemeshow } \\
\hline statistics & & 0.848 & 0.977 & 0.714 \\
\hline$\%$ Concordant & & 71.4 & 61.5 & 60.2 \\
\hline$\%$ Discordant & & 27.1 & 36.1 & 37.8 \\
\hline$\%$ Tied & & 1.6 & 2.4 & 2.1 \\
\hline
\end{tabular}

Note: D\&B data were from data records used for the sample selection and do not purport to be current data. 
TABLE 16

SUMMARY OF RESPONSE MODELS

\begin{tabular}{|c|c|c|c|c|}
\hline Variable & Level & High-Tech & Medium-Tech & Non-Tech \\
\hline $\begin{array}{l}\text { Census division } \\
\text { Sales volume (D\&B }\end{array}$ & 4 & Interaction & Main, Interaction & Main, Interaction \\
\hline Data) & 4 & Interaction & Main, Interaction & Main, Interaction \\
\hline Population size & 3 & Interaction & Main, Interaction & Main, Interaction \\
\hline $\begin{array}{l}\text { Own/Rent (D\&B Data) } \\
\text { Legal status (D\&B }\end{array}$ & 2 & & Main & \\
\hline Data) & 4 & Main, Interaction & Main, Interaction & Main, Interaction \\
\hline $\begin{array}{l}\text { D\&B Employee Count } \\
\text { Metropolitan Statistical }\end{array}$ & 3 & Interaction & Main, Interaction & Main \\
\hline Area (MSA) & 2 & & & Main, Interaction \\
\hline Woman-ownership & 2 & Interaction & Main, Interaction & Interaction \\
\hline Major industry & 5 & & & Main, Interaction \\
\hline Small business & 2 & & & Interaction \\
\hline Full R-square & & 0.0382 & 0.0286 & 0.0190 \\
\hline Reduced R-square & & 0.0370 & 0.0260 & 0.0163 \\
\hline $\begin{array}{l}\text { Hosmer-Lemeshow } \\
\text { statistics }\end{array}$ & & 0.491 & 0.867 & 0.941 \\
\hline$\%$ Concordant & & 60.3 & 57.7 & 56.5 \\
\hline$\%$ Discordant & & 38.6 & 40.5 & 42.2 \\
\hline$\%$ Tied & & 1.1 & 1.8 & 1.3 \\
\hline
\end{tabular}

Note: D\&B data were from data records used for the sample selection and do not purport to be current data.

\section{H. ESTIMATION}

\section{Point Estimation}

The sampling design for the KFS is a simple stratified sampling design. As described in Section $\mathrm{C}$, the businesses in the high-tech stratum were oversampled substantially (actually, all high-tech businesses in the frame were included in the sample). We also oversampled the medium-tech businesses relative to the non-tech businesses. The sampling weights take into account this oversampling to remove the potential bias in the estimates relative to unweighted estimates. Moreover, the KFS had an overall 43 percent response rate. As shown in Section G, the response rate was different by legal status, ownership, and geographic region. The nonresponse adjustments described in Section $G$ were designed to minimize the potential 
nonresponse bias in the estimates. We strongly recommend the use of the non-response-adjusted weights for all estimates using the KFS data.

\section{Variance and Interval Estimation}

Variance estimates calculated from KFS data must incorporate the sample design features in order to obtain the correct estimate. Most procedures in standard statistical packages, such as SAS, STATA, and SPSS, are not appropriate for the proposed design because the assumptions in these software packages or procedures are of independent, identically distributed observations or simple random sampling with replacement. ${ }^{12}$ Although the simple random sample variance may approximate the true sampling variance for some surveys, it is likely to underestimate substantially the sampling variance with the KFS design.

The sampling variance is a measure of the variation of an estimator attributable to having sampled a portion of the full population of interest using a specific probability-based sampling design. The sampling variance is a measure of the variation of the estimate of a population parameter (for example, a population mean or proportion) over repeated samples, whereas the classic "population" variance is a measure of the variation among the observations in the population. The population variance is different from the sampling variance in the sense that the population variance is a constant, independent of any sampling issues, while the sampling variance becomes smaller as the sample size increases. The sampling variance is zero when the full population is observed, as in a census.

For the KFS, the sampling variance estimate is a function of the sampling design and the population parameter being estimated, and it is called the design-based sampling variance. The design-based variance assumes the use of fully adjusted sampling weights. The fully adjusted

\footnotetext{
${ }^{12}$ STATA and SAS software packages contain procedures that account for the sampling design.
} 
sampling weights are derived from the sampling design with adjustments to compensate for locating the business and for nonresponse among the businesses and additional adjustments to align the sampling totals to external totals, as previously described. We developed a single fully adjusted sampling weight and information on analysis parameters (that is, analysis stratification) necessary for the estimation of the sampling variance for a statistic using the Taylor series linearization approach. The fully adjusted sampling weight and the analysis parameters can be used in survey data analysis procedures in SUDAAN or in select procedures in STATA and SAS to compute design-unbiased variance estimates. These variance estimates can be used to make interval estimates. For example, for a proportion $(p)$ of businesses (or owners) with certain characteristics, the 90 percent confidence interval is:

$$
[p-1.645 \times(\operatorname{std} \text { err. }(p)), \quad p+1.645 \times(\operatorname{std} \text { err. }(p))]
$$

To identify sampling levels or stages, the SUDAAN software requires specifying the survey design and STRATA variables. This is the stratum variable we used when drawing the sample (that is, the six-level variable defined by technology group and woman-owned status).

\section{Selected Estimates and Variances}

The point and variance estimation procedures are straightforward, and we provide example estimates at the business level and the owner level here. These estimates are for the following variables:

Business level:

- Percent of businesses that are new, independent businesses created by a single person or a team of people $(\mathrm{B} 1=3)$

- Percent of businesses that are sole proprietorships $(\mathrm{B} 2 \mathrm{a}=1)$

- Percent of businesses that are partnerships $(B 2 a=5,6)$ 
- Percent of businesses whose primary location is a residence such as a home or garage $(\mathrm{C} 8=1)$

- Percent of businesses that have any patents, copyrights, or trademarks (any D3 = 1)

- Percent of businesses that have $R \& D$ expenditures $(F 19=1)$

Owner level:

- Percent of owners who are $25-44(\mathrm{G} 4=2,3)$

- Percent of owners with higher than bachelor's degree $(\mathrm{G} 9=7,8,9,10)$

- Percent of women owners $(\mathrm{G} 10=2)$

These estimates and the standard errors (the square root of the variance) of these estimates are given in Table 17. 
TABLE 17

\section{VARIANCE ESTIMATION FOR SOME BUSINESS CHARACTERISTICS AND OWNER CHARACTERISTICS}

\begin{tabular}{|c|c|c|c|c|}
\hline & $\begin{array}{l}\text { High-Tech } \\
\text { Sampling } \\
\text { Strata }\end{array}$ & Sample Size & Estimate & $\begin{array}{l}\text { Standard } \\
\text { Error }\end{array}$ \\
\hline \multirow{4}{*}{$\begin{array}{l}\text { Percent of businesses that are new, independent, and } \\
\text { businesses created by a single person or a team of } \\
\text { people }\end{array}$} & All & 4,928 & 92.13 & 0.45 \\
\hline & High-Tech & 705 & 90.84 & 1.11 \\
\hline & Medium-Tech & 1,329 & 97.09 & 0.47 \\
\hline & Non-Tech & 2,894 & 91.39 & 0.52 \\
\hline \multirow[t]{4}{*}{ Percent of businesses that are sole proprietorships } & All & 4,928 & 35.76 & 0.79 \\
\hline & High-Tech & 705 & 22.65 & 1.62 \\
\hline & Medium-Tech & 1,329 & 30.96 & 1.26 \\
\hline & Non-Tech & 2,894 & 36.79 & 0.91 \\
\hline \multirow[t]{4}{*}{ Percent of businesses that are partnerships } & All & 4,928 & 5.46 & 0.38 \\
\hline & High-Tech & 705 & 4.09 & 0.75 \\
\hline & Medium-Tech & 1,329 & 3.56 & 0.52 \\
\hline & Non-Tech & 2,894 & 5.79 & 0.44 \\
\hline \multirow{4}{*}{$\begin{array}{l}\text { Percent of businesses that have any patents, copyrights, } \\
\text { trademarks }\end{array}$} & All & 4,924 & 19.53 & 0.65 \\
\hline & High-Tech & 704 & 32.30 & 1.80 \\
\hline & Medium-Tech & 1,327 & 23.40 & 1.18 \\
\hline & Non-Tech & 2,893 & 18.66 & 0.74 \\
\hline \multirow[t]{4}{*}{ Percent of businesses that have $R \& D$ expenditures } & All & 4,909 & 18.07 & 0.62 \\
\hline & High-Tech & 701 & 35.30 & 1.84 \\
\hline & Medium-Tech & 1,326 & 25.86 & 1.22 \\
\hline & Non-Tech & 2,882 & 16.49 & 0.71 \\
\hline \multirow{4}{*}{$\begin{array}{l}\text { Percent of businesses whose primary location is a } \\
\text { residence such as a home or garage }\end{array}$} & All & 4,922 & 49.21 & 0.82 \\
\hline & High-Tech & 705 & 37.43 & 1.84 \\
\hline & Medium-Tech & 1,328 & 64.72 & 1.33 \\
\hline & Non-Tech & 2,889 & 47.05 & 0.94 \\
\hline \multirow[t]{4}{*}{ Percent of owners who are $25-44$} & All & 4,905 & 51.09 & 0.83 \\
\hline & High-Tech & 701 & 40.80 & 1.88 \\
\hline & Medium-Tech & 1,325 & 48.26 & 1.39 \\
\hline & Non-Tech & 2,879 & 51.74 & 0.95 \\
\hline \multirow[t]{4}{*}{ Percent of owners with higher than a bachelor's degree } & All & 4,917 & 47.80 & 0.82 \\
\hline & High-Tech & 704 & 51.50 & 1.92 \\
\hline & Medium-Tech & 1,327 & 68.65 & 1.28 \\
\hline & Non-Tech & 2,886 & 44.48 & 0.94 \\
\hline \multirow[t]{4}{*}{ Percent of women owners } & All & 4,919 & 31.46 & 0.58 \\
\hline & High-Tech & 703 & 16.44 & 1.08 \\
\hline & Medium-Tech & 1,328 & 24.16 & 0.84 \\
\hline & Non-Tech & 2,888 & 32.91 & 0.67 \\
\hline
\end{tabular}

